\title{
Complete Genome Sequencing Provides Novel Insight Into the Virulence Repertories and Phylogenetic Position of Dry Beans Pathogen Curtobacterium flaccumfaciens pv. flaccumfaciens
}

\author{
Gongyou Chen, ${ }^{1}$ Moein Khojasteh, ${ }^{1,2}$ Ayat Taheri-Dehkordi, ${ }^{3}$ S. Mohsen Taghavi, ${ }^{2}$ Touraj Rahimi, ${ }^{4}$ and Ebrahim Osdaghi ${ }^{5, \dagger}$ \\ ${ }^{1}$ School of Agriculture and Biology/State Key Laboratory of Microbial Metabolism, Shanghai Jiao Tong University, Shanghai, 200240, China \\ ${ }^{2}$ Department of Plant Protection, College of Agriculture, Shiraz University, Shiraz 71441-65186, Iran \\ ${ }^{3}$ Department of Horticultural Science, College of Agriculture \& Natural Resources, University of Tehran, Karaj 31587-77871, Iran \\ ${ }^{4}$ Department of Agronomy and Plant Breeding, Shahr-e-Qods Branch, Islamic Azad University, Tehran, Iran \\ 5 Department of Plant Protection, College of Agriculture, University of Tehran, Karaj 31587-77871, Iran \\ Accepted for publication 24 July 2020.
}

\begin{abstract}
Bacterial wilt of dry beans (family Fabaceae) caused by the actinobacterial agent Curtobacterium flaccumfaciens pv. flaccumfaciens is one of the most important diseases threatening edible legume production around the globe. Despite the economic losses due to the bacterial wilt disease, the pathogen has not so far been investigated for its genomic features, pathogenicity determinants, and virulence strategies. Here we present the first complete genome sequence of a highly virulent bacteriocin-producing C. flaccumfaciens pv. flaccumfaciens strain P990. The bacterium has a circular chromosome consisting of 3,736 kbp with the $\mathrm{G}+\mathrm{C} \%$ content of $71.0 \%$. Furthermore, a 147-kbp circular plasmid (pCff1) with $66.1 \% \mathrm{G}+\mathrm{C} \%$ content as well as two circular plasmid-like DNAs with sizes of 25 and 22 kbp were detected within the genomic contents of $C$. flaccumfaciens pv. flaccumfaciens. Phylogenetic analyses revealed that only a few number of Curtobacterium sp. strains deposited in the public databases could be classified within the species $C$. flaccumfaciens. Comparative genomics of
\end{abstract}

ABSTRACT

C. flaccumfaciens pv. flaccumfaciens using the genome sequences of actinobacterial plant pathogens revealed the presence of a set of unique low $\mathrm{G}+\mathrm{C} \%$ content genomic islands in the C. flaccumfaciens $\mathrm{pv}$. flaccumfaciens genome. Homologs of pathogenicity-determinant loci capable of producing 1,4-beta-xylanase (xysA), pectate lyase (pelAl and pelA2), serine protease ( $\operatorname{ch} p C, \operatorname{chp} G$, and pat-1), and sortase ( $\operatorname{st} t A)$ were detected in $C$. flaccumfaciens pv. flaccumfaciens genome. The genomic data presented here extend our understanding of the $C$. flaccumfaciens pv. flaccumfaciens genomic features and pave the ways of research on functional and interaction genetics to combat the risk of bacterial wilt disease in the 21st century's dry bean industry.

Keywords: actinobacteria, bacterial pathogens, bacterial wilt, coryneform bacteria, Fabaceae, leguminous, Microbacteriaceae, quarantine pathogen, $\tan$ spot
Bacterial wilt of dry beans (family Fabaceae) caused by a Grampositive actinobacterial agent Curtobacterium flaccumfaciens pv. flaccumfaciens is one of the most important biotic constraints affecting edible legumes' production around the globe (Harveson et al. 2015). C. flaccumfaciens pv. flaccumfaciens is included in the A2 (high risk) list of quarantine pathogens by the European and Mediterranean Plant Protection Organization; hence, it is under strict quarantine control and zero tolerance in several countries (EPPO 2011). C. flaccumfaciens pv. flaccumfaciens is the only member of six pathovars within the species $C$. flaccumfaciens that is reported to have wide geographic distribution and causes economic yield losses on the respective host plants (Evtushenko and Takeuchi 2006). Host range of the pathogen includes common bean (Phaseolus vulgaris), cowpea (Vigna unguiculata), mung bean (Vigna radiata), soybean (Glycine max), and a number of wild leguminous plants (Huang et al. 2009; Osdaghi et al. 2015a). C. flaccumfaciens pv. flaccumfaciens is well known among plant pathogenic bacteria for its multicolored colony variants possessing yellow, orange, pink, purple,

${ }^{\dagger}$ Corresponding author: E. Osdaghi; eosdaghi@ut.ac.ir

Funding: This study was financially supported by Shanghai Jiao Tong University, Agriculture Applied Technology Development Program, China (grant number 202002080008F01462) and Shiraz University, Iran.

*The $\boldsymbol{e}$-Xtra logo stands for "electronic extra" and indicates that five supplementary figures are published online.

The author(s) declare no conflict of interest.

(C) 2021 The American Phytopathological Society and red colonies on culture media (Osdaghi et al. 2016), while yellow-pigmented strains are more prevalent and aggressive compared with the other variants (Osdaghi et al. 2020a). Disease symptoms include interveinal flaccidity and chlorosis on leaflets leading to tissue necrosis on leaves surrounded by chlorotic margins. Subsequent symptoms are leaf wilting during periods of moisture stress, overall wilting and entire plant death in the case of severe infections and favorite environmental conditions (Harveson et al. 2015). Seed coat discoloration into yellow, orange, or purple is a common symptom in white-seeded common bean cultivars (Harveson 2013).

Bacterial wilt was first observed and described in South Dakota (United States) in 1922 (Hedges 1922). Subsequently, the disease was reported in several Midwestern and Northern states of the United States, as well as Canada and Mexico until the mid-20th century. During the past decades, the pathogen was reported in Australia, Europe, Asia, and Africa leading to substantial economic losses on different dry bean species (EPPO 2011; Osdaghi et al. 2020a). Regarding its seedborne nature, the pathogen is capable of distributing in long distances via infected seed lots, being established in the areas with no history of the disease (EPPO 2011). Since the use of conventional pesticides and chemicals have limited effect on the control of bacterial wilt, use of pathogen-free highquality seed lots, crop sanitary, and resistant cultivars play a pivotal role in the management of the disease (Harveson et al. 2015).

Despite the economic importance of the bacterial wilt disease in dry beans industry, the causal agent has not so far been investigated for its molecular characteristics and virulence repertories. Indeed, among the Gram-positive bacterial plant pathogens, $C$. flaccumfaciens pv. flaccumfaciens is the least studied member in terms of genomic 
features and pathogenicity determinants (Osdaghi et al. 2020b; Thapa et al. 2019). This could be due in part to the fact that molecular manipulation technologies and transformation protocols (e.g., plasmid vectors required for cloning and mutagenesis) have not yet been developed for the bacterium, while all these technologies are available for the other actinobacterial plant pathogens, e.g., the tomato pathogen Clavibacter michiganensis (Meletzus and Eichenlaub 1991). It has been shown that pathogenicity of Clavibacter michiganensis is attributed to a low $\mathrm{G}+\mathrm{C} \%$ content genomic island (GI) harboring virulence-inducing loci. Most of the Gram-positive plant pathogenic bacteria produce lytic enzymes, plasmids, as well as toxic compounds to trigger disease on their host plants (Gartemann et al. 2008). However, none of these features has so far been determined to be involved in the pathogenicity of $C$. flaccumfaciens pv. flaccumfaciens (Osdaghi et al. 2020a).

By the beginning of the genomic era, high throughput complete genome sequencing initiated a substantial advancement in the understanding of molecular mechanisms underlying plant colonization, pathogenicity, and survival mechanisms of phytopathogenic actinobacteria (Thapa et al. 2019). In 2004, complete genome sequence of sugarcane pathogen Leifsonia xyli subsp. xyli has provided the early perceptions from the genomic repertories of Gram-positive phytopathogens (Monteiro-Vitorello et al. 2004). However, the main expansion in the breadth of knowledge from these bacteria was made by the whole genome sequencing of tomato and potato pathogens Clavibacter michiganensis and Clavibacter sepedonicus, respectively (Gartemann et al. 2008, Bentley et al. 2008). During the subsequent years, whole genome sequences of nearly all plant pathogenic members of the family Microbacteriaceae became available except for the pathovars of $C$. flaccumfaciens. So far, all the genome sequences assigned as Curtobacterium spp. or C. flaccumfaciens in the public databases belong to nonpathogenic members of the genus, lacking key information about the pathogenicity mechanisms of such an omnivorous cosmopolite group of bacteria (Osdaghi et al. 2018a). Hence, complete genome sequence of the bacterial wilt pathogen will integrate our understanding from the ecology and epidemiology of the pathogen into genomic characteristics and virulence repertories of the bacterium, as well as putative molecular mechanisms underlying disease development in the host plants.

The main purposes of the present study were to (i) obtain the complete genome sequence of a highly virulent bacteriocinproducing strain of $C$. flaccumfaciens pv. flaccumfaciens, (ii) determine genomic features of the pathogen to provide an insight into its virulence and survival mechanisms, and (iii) evaluate whether or not the key phenotypic features could be traced within the genome of the pathogen. With this aim, we have sequenced the whole genomic DNA of the strain P990 and analyzed the resulting data using comparative genomics against the nonpathogenic counterparts of $C$. flaccumfaciens as well as previously reported genome sequences of plant pathogenic actinobacteria.

\section{MATERIALS AND METHODS}

Bacterial strain, culture media, and DNA extraction. Yellow-pigmented C. flaccumfaciens pv. flaccumfaciens strain P990 (ICMP 22053), which was isolated from the phyllosphere of asymptomatic bell pepper (Capsicum annuum) in Iran in 2014, was used for complete genome sequencing (Osdaghi et al. 2018a). The strain P990 was shown to have fluidal colonies (means that the colony flowed when culture plates were inclined at $45^{\circ}$ ) on yeast extract-dextrose-calcium carbonate (YDC) agar medium and capable of producing bacteriocin against other $C$. flaccumfaciens pv. flaccumfaciens strains on agar-based culture media (Osdaghi et al. 2018b). The bacterial strain was restreaked on yeast-extract peptone glucose agar (YPGA) medium, resuspended in sterile distilled water (SDW) and stored at $4^{\circ} \mathrm{C}$ for further use. For the longterm storage, the strain was maintained in $15 \%$ glycerol at $-70^{\circ} \mathrm{C}$.
Whole genomic DNA extraction was carried out using Expin Combo GP (GeneAll, Tic Tech Centre, Singapore) DNA extraction kit from the $24 \mathrm{~h}$ culture in lysogeny broth (LB) medium as recommended by the manufacturer. The quality and quantity of the DNA were spectrophotometrically evaluated and adjusted to 1,500 ng/ $\mu \mathrm{l}$ using NanoDrop ND-100 (NanoDrop Technologies, Waltham, MA, U.S.A.) as described previously (Khojasteh et al. 2020). In order to ensure the identity of the bacterial strain, the purified DNA was tested using the $C$. flaccumfaciens pv. flaccumfaciens-specific PCR primer pair CffFOR2/CffREV4 (Tegli et al. 2002) using the procedure described previously (Osdaghi and Lak 2015).

Pathogenicity and host range assays. The strain P990 was subjected to pathogenicity and host range assays in greenhouse conditions using the procedure described previously (Osdaghi et al. 2015b). Pathogenicity tests were performed on bell pepper (cultivar Sereno), chili pepper (cultivar Aziz), common bean (cultivars Red Kidney, Pinto, and Navy), cowpea (cultivar Partow), mung bean (cultivar Mashhad), soybean (cultivar Katool), and tomato (cultivar Sunseed 6189) plants. Plant growth conditions, inoculation procedure, and incubation environment were the same as detailed previously (Sedighian et al. 2020). In brief, the plants were inoculated at 5 to 15 days postemergence depending on the stage of growth of the species. Inoculation was made by inserting a sterile dissecting needle dipped into a freshly prepared bacterial suspension $\left(1 \times 10^{8} \mathrm{CFU} / \mathrm{ml}\right)$ through the first internode of each plant (Ansari et al. 2019). Inoculated plants were periodically monitored for the appearance of disease symptoms up to 30 days postinoculation (dpi). Positive and negative control plants were treated in the same manner using the type strain of $C$. flaccumfaciens pv. flaccumfaciens (ICMP 2584T; isolated from common bean in Hungary in 1957) and SDW, respectively. Koch's postulates were accomplished by reisolating the inoculated strain on YPGA medium from all inoculated plants showing wilt symptoms. Confirmation of the identity of the reisolated bacteria was made by determining Gram reaction and colony characteristics on YDC agar medium, as well as using the pathovar-specific primer pair CffFOR2/CffREV4 (Tegli et al. 2002).

Furthermore, a cell-free culture filtrate of the strain P990 was evaluated for its effect on common bean seedlings to determine whether any toxic compound is attributed to the pathogenicity of the bacterium. With this aim, the strain P990 was grown in liquid LB medium for $24 \mathrm{~h}$, centrifuged in $11,000 \times g$ for $10 \mathrm{~min}$ to remove the bacterial cells, and the supernatant was sterilized by tyndallization through three successive days. In order to approve the sterility of the final substrate, $20 \mu \mathrm{l}$ of the culture filtrate was spread onto freshly prepared YDC agar plates and incubated in $27^{\circ} \mathrm{C}$ for $48 \mathrm{~h}$. To prepare different concentrations of the culture filtrate (i.e., 1/2, 1/4, and $1 / 8$ of the original concentration), 62.5, 125, and $250 \mathrm{ml}$ aliquots were separately added to $250 \mathrm{ml}$ of SDW. Subsequently, five common bean seedlings grown on sterilized perlite ( 6 to 7 days old) pulled out, their roots were rinsed three times in sterile water and dipped into the culture filtrate. The seedlings were incubated under ambient conditions for $5 \mathrm{dpi}$. Control seedlings were dipped into the same volume and same concentrations of uninoculated LB medium as well as SDW. The substrate was considered as toxic if the seedlings showed wilting symptoms within $5 \mathrm{dpi}$. To ensure that the symptoms were not attributed to bacterial colonization, Koch's postulates were accomplished on YPGA medium for the seedlings showing wilt symptoms using the procedure as described above. All the pathogenicity and bioassay tests were conducted at least twice.

Genome sequencing, assembly, and annotation. Genome sequencing and database construction were performed by Shanghai Ouyi Biomedical Technology Co. (Shanghai, China) using Oxford Nanopore sequencing technologies according to the recommendations from the manufacture. Nanopore data were used for de novo genome assembly using Flye service (Kolmogorov et al. 2019). The assembled genome was subjected to coding gene prediction using 
online service Prokaryotic Dynamic Programming Genefinding Algorithm, prodigal v2.6.3. Furthermore, RNAscan-SE v1.3.1, RNAmmer v1.2, and Rfam v10.0 services were used to predict tRNA, rRNA and RNA families, respectively. Publicly available databases, i.e., NR annotations, CAZy (carbohydrate-active enzymes), COG (clusters of orthologous groups), eggNOG (evolutionary genealogy of genes: nonsupervised orthologous groups), GO (gene ontology), KEGG (Kyoto encyclopedia of genes and Genomes), VFDB (virulence factor database), Pfam, as well as PHI-base (pathogen and host interaction database) were used for genomics analyses and inferring functional properties of C. flaccumfaciens pv. flaccumfaciens genes. For NR, COG/KOG, GO, Swissprot, eggNOG, and KEGG database annotations, we used diamond software for comparison (Buchfink et al. 2015). We also used HMMER3 software and searched against Pfam database to allocate protein families within the C. flaccumfaciens pv. flaccumfaciens genome (El-Gebali et al. 2019). Subsequently, genome annotation was performed using the GeneMarkS+ v4.6 suite implemented in the NCBI Prokaryotic Genome Annotation Pipeline with default settings (Borodovsky and Lomsadze 2014). Total number of protein-coding genes, RNA genes, and pseudogenes were determined for the genome. Furthermore, the Circos software v0.69 was employed to generate a circular map of the C. flaccumfaciens pv. flaccumfaciens genome (Krzywinski et al. 2009), while IslandViewer 4 was used for the identification and visualization of GIs (Bertelli et al. 2017).

Phylogenetic analyses. In order to determine the precise phylogenetic position of the strain P990, all the publicly available genome sequences assigned as Curtobacterium spp. were retrieved from the NCBI GenBank database (up to February 2020) and included in the phylogenetic analyses. Average nucleotide identity (ANI) was calculated among all the Curtobacterium spp. genome sequences included in this study. The ANI was estimated using both one-versus-one and all-versus-all strategies via different algorithms i.e., JSpeciesWS (Richter et al. 2016), ANI calculator (Rodriguez-R and Konstantinidis 2016), and OrthoANIu (Yoon et al. 2017). ANIbased neighbor joining phylogenetic trees were constructed using the ANI calculator online service, first for all the Curtobacterium spp. strains, and then for the representative species of all the plant pathogenic actinobacteria using the procedure described previously (Osdaghi et al. 2020b). Additionally, genome-to-genome distance calculator (GGDC, v2.1) online service was used to calculate digital DNA-DNA hybridization (dDDH) value, which infers to the genome-to-genome distances between pairs of genomes based on the genome blast distance phylogeny (Meier-Kolthoff et al. 2013). A combination of ANI and dDDH indices was used to designate a taxonomic status to a given taxon where the "stand-alone species" status was assigned to a taxon when both ANI and dDDH values were below the accepted threshold, i.e., $\leq 95 \%$ and $\leq 70 \%$ for ANI and dDDH, respectively (Kim et al. 2014).

Comparative genomics. Based on the results obtained from the phylogenetic analyses, P990 was subjected to comparative genomics against two $C$. flaccumfaciens strains, four phylogenetically closely related Curtobacterium spp. strains to $C$. flaccumfaciens pv. flaccumfaciens, as well as seven economically important actinobacterial species, which represent the entire genetic diversity of plant-associated actinobacteria based on ANI/dDDH, host of isolation, and pathogenicity characteristics (Thapa et al. 2019). The online annotation service RAST (Aziz et al. 2008) was used for fully automated annotation of the bacterial genomes and the obtained information was used to reconstruct metabolic networks and

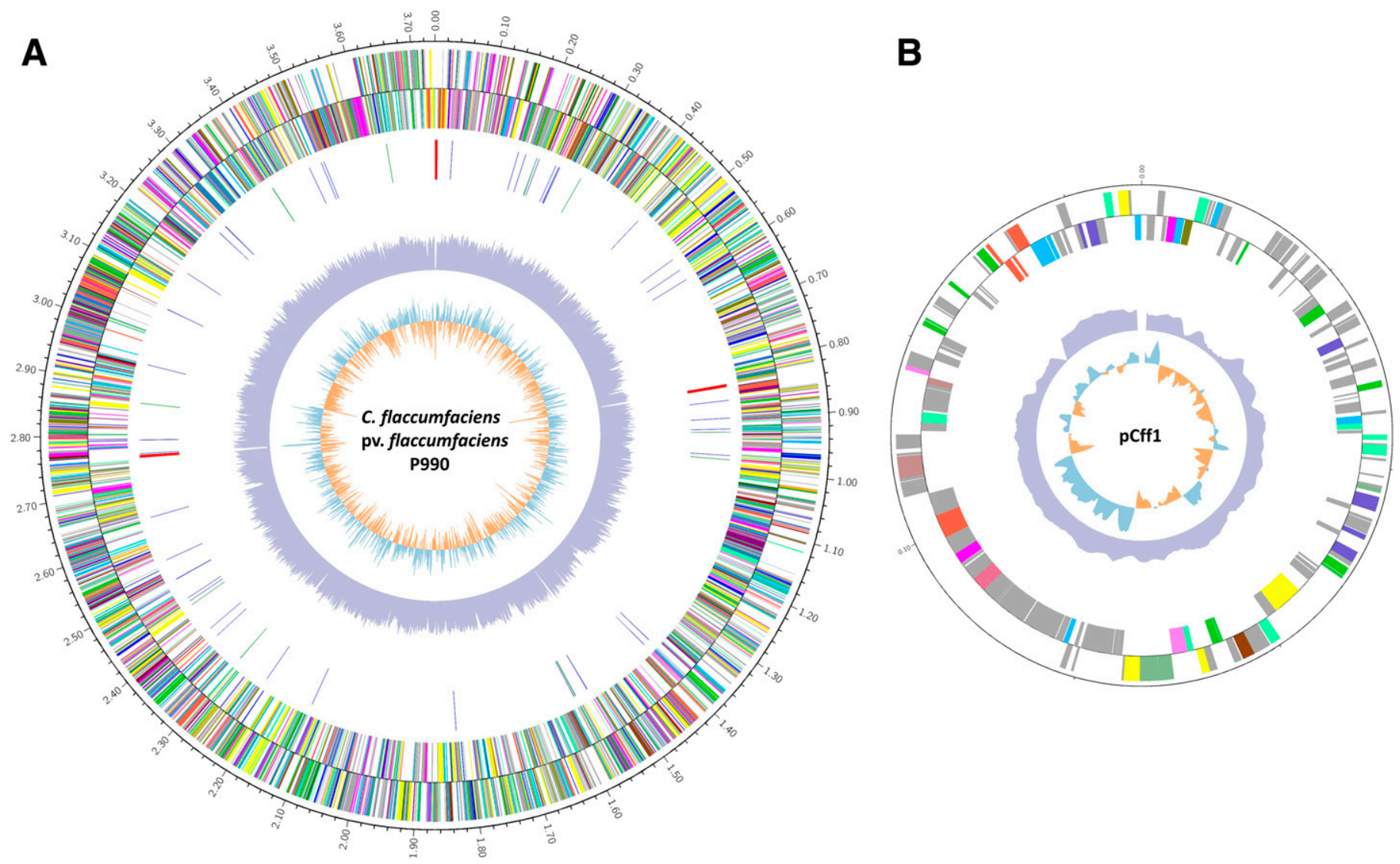

Fig. 1. Circular map of A, Curtobacterium flaccumfaciens pv. flaccumfaciens 9990 chromosomal DNA and B, plasmid pCff1 DNA generated using Circos software v0.69. In the chromosomal DNA map, from the outermost to innermost the circles show nucleotide numbering (circle 1), COG annotation of forward (circle 2) and reverse (circle 3) strands, noncoding RNAs (rRNA red, tRNA blue, sRNA green; circle 4), GC content (circle 5), and GC skew (circle 6). 
TABLE 1. List of genomic islands in the chromosomal DNA and plasmid pCff1 DNA of Curtobacterium flaccumfaciens pv. flaccumfaciens P990 detected using IslandViewer 4

\begin{tabular}{|c|c|c|c|c|c|c|}
\hline Number & Island start & Island end & Length & Specificity & $\mathrm{G}+\mathrm{C} \%$ & Gene content \\
\hline \multicolumn{7}{|c|}{ Islands on chromosome } \\
\hline I & 305,117 & 315,177 & 10,060 & + & 73.38 & $\begin{array}{l}\text { Hypothetical protein (3), 3,4-dihydroxy-2-butanone-4-phosphate synthase, 6,7-dimethyl- } \\
\text { 8-ribityllumazine synthase, GNAT family N-acetyltransferase, MFS transporter, phage } \\
\text { holin family protein, riboflavin synthase, TetR family transcriptional regulator, winged } \\
\text { helix-turn-helix transcriptional regulator }\end{array}$ \\
\hline II & 445,487 & 451,733 & 6,246 & + & 64.21 & Hypothetical protein (14) \\
\hline III & 719,074 & 724,308 & 5,234 & + & 66.76 & $\begin{array}{l}\text { Hypothetical protein (4), ABC transporter permease, alpha/beta fold hydrolase, ATP- } \\
\text { binding cassette domain-containing protein, methyltransferase domain-containing } \\
\text { protein, response regulator, transcriptional regulator }\end{array}$ \\
\hline IV & 748,694 & 758,824 & 10,130 & + & 71.07 & $\begin{array}{l}\text { Hypothetical protein (3), phosphate } \mathrm{ABC} \text { transporter permease PstA, phosphate } \mathrm{ABC} \\
\text { transporter permease subunit PstC, phosphate } \mathrm{ABC} \text { transporter substrate-binding protein } \\
\text { PstS, sortase }\end{array}$ \\
\hline V & 787,302 & 791,353 & 4,051 & - & 64.98 & $\begin{array}{l}\text { Hypothetical protein (2), CPBP family intramembrane metalloprotease, DUF1648 } \\
\text { domain-containing protein, HTTM domain-containing protein, SdpA family } \\
\text { antimicrobial peptide system protein }\end{array}$ \\
\hline VI & $1,319,540$ & $1,324,587$ & 5,047 & + & 67.97 & $\begin{array}{l}\text { 30S ribosomal protein S18, 50S ribosomal protein L9, AAA family ATPase, DDE-type } \\
\text { integrase/transposase/recombinase, DEAD/DEAH box helicase, DoxX family } \\
\text { membrane protein, DUF4209 domain-containing protein, EamA family transporter, } \\
\text { GntR family transcriptional regulator, ImmA/IrrE family metallo-endopeptidase, low } \\
\text { molecular weight phosphatase family protein, Lsr2 family protein, metalloregulator } \\
\text { ArsR/SmtB family transcription factor, NAD(P)-binding domain-containing protein, } \\
\text { replicative DNA helicase, single-stranded DNA-binding protein }\end{array}$ \\
\hline VII & $1,488,523$ & $1,492,942$ & 4,419 & - & 55.97 & TIR domain-containing protein \\
\hline VIII & $1,577,417$ & $1,582,572$ & 5,155 & + & 68.64 & $\begin{array}{l}\text { AAA family ATPase, EamA family transporter, HAD-IB family hydrolase, MFS } \\
\text { transporter, zinc-binding dehydrogenase }\end{array}$ \\
\hline IX & $1,584,727$ & $1,589,583$ & 4,856 & + & 70.81 & $\begin{array}{l}\text { Beta-ketoacyl-ACP synthase III, helix-turn-helix domain-containing protein, MBL fold } \\
\text { metallo-hydrolase, NAD(P)-binding domain-containing protein }\end{array}$ \\
\hline $\mathrm{X}$ & $1,604,094$ & $1,621,881$ & 17,787 & + & 66.69 & $\begin{array}{l}\text { DUF11 domain-containing protein, DUF4190 domain-containing protein, helix-turn-helix } \\
\text { domain-containing protein, LysR family transcriptional regulator, oxidoreductase, } \\
\text { phospholipase, SDR family oxidoreductase, TetR family transcriptional regulator, TIR } \\
\text { domain-containing protein, tryptophan-tRNA ligase }\end{array}$ \\
\hline XI & $1,653,610$ & $1,662,856$ & 9,246 & - & 70.91 & $\begin{array}{l}\text { DUF3494 domain-containing protein, GAF domain-containing protein, HupE/UreJ family } \\
\text { protein, metallophosphoesterase, ROK family protein }\end{array}$ \\
\hline XII & $1,728,686$ & $1,736,488$ & 7,802 & + & 64.42 & $\begin{array}{l}\text { Cupin domain-containing protein, DUF4231 domain-containing protein, FAD-dependent } \\
\text { oxidoreductase, helix-turn-helix domain-containing protein, recombinase family protein }\end{array}$ \\
\hline XIX & $3,255,741$ & $3,269,226$ & 13,485 & + & 70.53 & $\begin{array}{l}\text { Alcohol dehydrogenase catalytic domain-containing protein, alpha/beta fold hydrolase, } \\
\text { catalase, DUF1345 domain-containing protein, GNAT family N-acetyltransferase, MFS } \\
\text { transporter }\end{array}$ \\
\hline $\mathrm{XX}$ & $3,425,557$ & $3,431,948$ & 6,391 & + & 70.90 & $\begin{array}{l}\text { Acyltransferase, GAF domain-containing protein, helix-turn-helix domain-containing } \\
\text { protein, isoprenylcysteine carboxylmethyltransferase family protein, NAD(P)-dependent } \\
\text { oxidoreductase }\end{array}$ \\
\hline XXI & $3,433,625$ & $3,437,682$ & 4,057 & + & 73.95 & $\begin{array}{l}\text { Chromate efflux transporter, glycosyltransferase, heat-shock protein HtpX, helix-turn- } \\
\text { helix domain-containing protein }\end{array}$ \\
\hline XXII & $3,455,324$ & $3,463,089$ & 7,765 & + & 70.98 & $\begin{array}{l}\text { ABC transporter permease subunit, extracellular solute-binding protein, } \\
\text { glycosyltransferase, heme utilization protein, inositol monophosphatase, substrate- } \\
\text { binding domain-containing protein }\end{array}$ \\
\hline XXIII & $3,463,206$ & $3,469,631$ & 6,425 & + & 71.13 & $\begin{array}{l}\text { Cation:dicarboxylase symporter family transporter, glycosyl transferase, LysM } \\
\text { peptidoglycan-binding domain-containing protein }\end{array}$ \\
\hline XXIV & $3,709,160$ & $3,714,691$ & 5,531 & - & 65.04 & $\begin{array}{l}\text { DNA mismatch endonuclease Vsr, DUF } 2075 \text { domain-containing protein, DUF871 family } \\
\text { protein, NUDIX domain-containing protein }\end{array}$ \\
\hline \multicolumn{7}{|c|}{ Islands on plasmid pCff1 } \\
\hline 1 & 7,966 & 23,061 & 15,095 & - & 59.92 & $\begin{array}{l}\text { Hypothetical protein (6), IS481 family transposase, pectate lyase, S1 family peptidase (2), } \\
\text { trypsin-like peptidase domain-containing protein, tyrosine-type recombinase/integrase }\end{array}$ \\
\hline 2 & 55,043 & 59,370 & 4,327 & - & 67.11 & $\begin{array}{l}\text { Carbohydrate } \mathrm{ABC} \text { transporter permease, extracellular solute-binding protein, glycosyl } \\
\text { hydrolase family, sugar } \mathrm{ABC} \text { transporter permease }\end{array}$ \\
\hline 3 & 104,029 & 108,776 & 4,747 & - & 68.29 & Cell division protein FtsK, conjugal transfer protein, hypothetical protein (5) \\
\hline 4 & 120,066 & 146,838 & 26,772 & - & 66.39 & $\begin{array}{l}\text { Dihydroxy-acid dehydratase, DUF1190 domain-containing protein, DUF2167 domain- } \\
\text { containing protein, DUF4129 domain-containing protein, DUF4350 domain-containing } \\
\text { protein, DUF58 domain-containing protein, gamma carbonic anhydrase family protein } \\
\text { (2), glutathionylspermidine synthase family protein, hypothetical protein (3), IS3 family } \\
\text { transposase (2), Lrp/AsnC family transcriptional regulator, MFS transporter, MoxR } \\
\text { family ATPase, PQQ-dependent sugar dehydrogenase, RDD family protein, stage II } \\
\text { sporulation protein M, transposase (2), venom serine protease KN13 }\end{array}$ \\
\hline
\end{tabular}


subsystems. A subsystem is a set of functional roles that the annotator considers as related categories. Subsystems represent a collection of functionally related protein families that make up a metabolic pathway (e.g., iron acquisition and metabolism), a complex (e.g., the ribosome), or a class of proteins (e.g., bacteriocins) (Overbeek et al. 2005). Subsequently, the genomes were transferred to the comparative environment of the SEED-Viewer (Overbeek et al. 2014) for comparative genomics analyses. The SEED-Viewer was used for the identification of protein-encoding sequences (CDS), assigning functions to the genes, and prediction of represented gene clusters in the genomes. Distribution of the genes among various clusters and specific protein-encoding genes within each cluster were estimated using the same service.

Furthermore, BLASTx-based investigation was performed to decipher whether the major pathogenicity determinant genes/ clusters in plant pathogenic actinobacteria are present in the C. flaccumfaciens pv. flaccumfaciens genome. Hence, one-versusone BLASTx search was accomplished against the sequences of the pathogenicity island (a 129-kb low $\mathrm{G}+\mathrm{C}$ region that includes $c h p$ and tomA clusters) as well as several individual genes proposed to have an effective contribution to the virulence of plant pathogenic bacteria within the family Microbacteriaceae (Thapa et al. 2019). Proteins with amino acid sequence similarities higher than $50 \%$ and with a query coverage higher than $70 \%$ were considered homologous. We also screened the genome sequence of P990 for the presence of hypothetical bacteriocin-encoding genes/clusters using the web-based tool BAGEL4 (De Jong et al. 2006). BAGEL4 combines direct mining for the structural genes with indirect mining for bacteriocin-associated genes. Furthermore, the online service PlasmidFinder 2.0 (Carattoli et al. 2014) was used to screen the genome of $\mathrm{P} 990$ for the presence of integrative plasmids/episomes. Identification and annotation of prophage sequences within the P990 genome were performed using the online service PHASTER (Arndt et al. 2016). Given the fact that identification of overlaps among the orthologous clusters can enable us to elucidate the function and evolution of proteins across multiple species, genomewide comparisons and visualization of orthologous clusters were performed using the online service OrthoVenn (Wang et al. 2015).
The analyses were conducted on the "bacteria" section of the platform using default settings (E-value: 1e-5, and inflation value: 1.5). Regarding the numeric limitation of OrthoVenn to handle the bacterial genomes (up to six genomes per run), different series of the strains were evaluated using the same parameters.

Pairwise genome collinearity alignment of the strain P990 with the above-mentioned representative actinobacterial strains was performed and visualized by BRIG 0.95 . BRIG is a Java-based tool for visualizing the comparison of a reference sequence to a set of query sequences. Results are plotted as a series of rings, each representing a query sequence, which are colored to indicate the presence of hits to the reference sequence. BRIG indicates which regions of the reference sequence are present/absent in query sequences (Alikhan et al. 2011). Moreover, Mauve software was used to illustrate locally collinear blocks among the genome of P990 and those of the representative actinobacterial strains mentioned above. Mauve is a Java-based tool for multiple alignments of whole genomes that identifies blocks of sequence homology and assigns each block a unique color. Each genome can then be visualized as a sequence of these colored blocks, facilitating visualization of the genome comparisons. This makes it easy to identify regions that are conserved among the whole set of input genomes (Darling et al. 2010).

Data availability. The dataset produced in this whole-genome sequencing project is available at the DDBJ/EMBL/GenBank database under accession numbers CP045287 to CP045290. A pure culture of the strain P990 is deposited in the International Collection of Microorganisms from Plants (ICMP, Auckland, New Zealand) and is available under the accession number ICMP 22053. The data that support the findings of this study are openly available in the NCBI GenBank database.

\section{RESULTS}

Pathogenicity and host range of P990. Among the seven crop species inoculated with P990, common bean, cowpea, mung bean, and soybean plants showed typical symptoms of bacterial wilt disease at 6 to $15 \mathrm{dpi}$. Interveinal chlorosis leading to necrotic areas
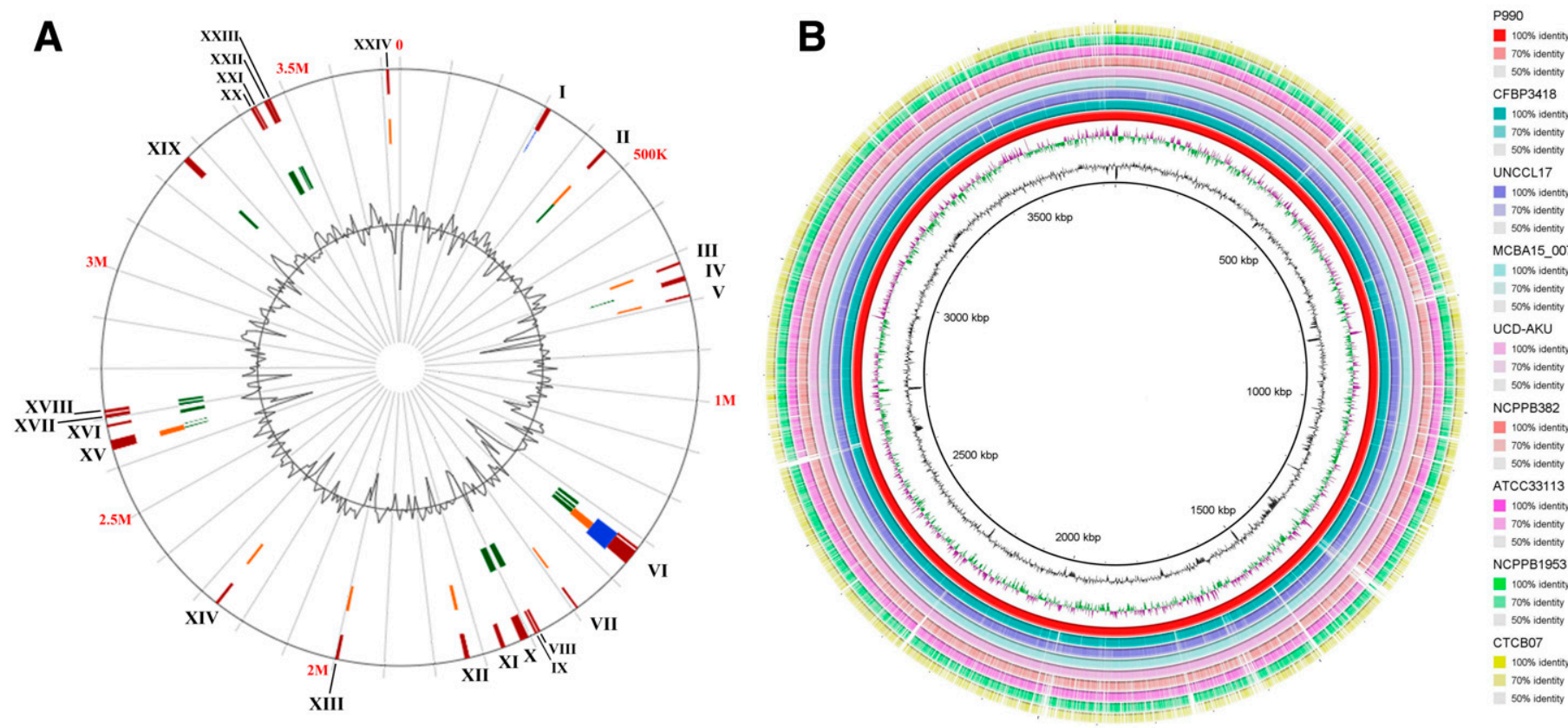

Fig. 2. A, Visualization of genomic islands (GI) in the chromosomal DNA of Curtobacterium flaccumfaciens pv. flaccumfaciens P990 using IslandViewer 4, and B, pairwise genome collinearity alignment of the same strain with the representative actinobacterial strains (Table 3) generated by BRIG 0.95. IslandViewer has identified 24 GIs on the chromosome of P990 within the range of 4,051 bp (GI-V) and 17,787 bp (GI-X), while 12 out of 24 GIs had $<70 \%$ G+C\% content, and 18 GIs were $C$. flaccumfaciens pv. flaccumfaciens-specific, in which $>70 \%$ of the nucleotide content did not occur in the nonpathogenic Curtobacterium spp. strains. 


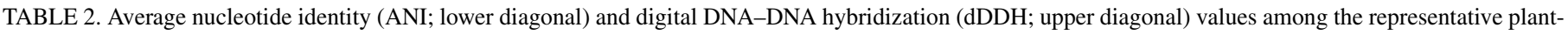
associated actinobacterial strains ${ }^{\text {a }}$

\begin{tabular}{|c|c|c|c|c|c|c|c|c|c|c|c|c|c|c|c|c|}
\hline Strain & Number & 1 & 2 & 3 & 4 & 5 & 6 & 7 & 8 & 9 & 10 & 11 & 12 & 13 & 14 & 15 \\
\hline C. flaccumfaciens pv. flaccumfaciens $\mathrm{P} 990$ & 1 & $\ldots$ & 74 & 73 & 63 & 63 & 52 & 52 & 28 & 28 & 26 & 26 & 20 & 20 & 19 & 19 \\
\hline \multicolumn{17}{|l|}{ C. flaccumfaciens pv. flaccumfaciens CFBP } \\
\hline $3418^{\mathrm{T}}$ & 2 & 97 & $\ldots$ & 74 & 63 & 64 & 53 & 53 & 28 & 28 & 26 & 26 & 19 & 20 & 19 & 19 \\
\hline C. flaccumfaciens MMLR14-014 & 3 & 97 & 97 & $\ldots$ & 64 & 65 & 53 & 53 & 28 & 29 & 26 & 26 & 20 & 20 & 19 & 19 \\
\hline Curtobacterium sp. UNCCL17 & 4 & 95 & 95 & 96 & $\ldots$ & 83 & 50 & 51 & 28 & 28 & 26 & 26 & 20 & 20 & 19 & 19 \\
\hline Curtobacterium sp. MCBA15-005 & 5 & 95 & 96 & 96 & 98 & $\ldots$ & 51 & 51 & 53 & 28 & 26 & 26 & 20 & 20 & 19 & 19 \\
\hline Curtobacterium sp. MCBA15-007 & 6 & 94 & 94 & 94 & 93 & 93 & $\ldots$ & 90 & 28 & 28 & 26 & 26 & 19 & 20 & 19 & 20 \\
\hline Curtobacterium sp. UCD-AKU & 7 & 94 & 94 & 94 & 93 & 92 & 99 & $\ldots$ & 28 & 28 & 26 & 26 & 19 & 20 & 19 & 20 \\
\hline Curtobacterium sp. BH-2-1-1 & 8 & 85 & 85 & 84 & 84 & 85 & 85 & 85 & $\ldots$ & 35 & 27 & 27 & 20 & 19 & 19 & 19 \\
\hline C. pusillum AA3 & 9 & 85 & 85 & 85 & 85 & 85 & 85 & 85 & 88 & $\ldots$ & 27 & 27 & 20 & 20 & 20 & 19 \\
\hline Curtobacterium sp. MR-MD2014 & 10 & 84 & 84 & 83 & 85 & 84 & 84 & 84 & 85 & 85 & $\ldots$ & 40 & 20 & 20 & 20 & 20 \\
\hline Curtobacterium sp. SGAir0471 & 11 & 84 & 84 & 83 & 83 & 84 & 84 & 84 & 85 & 85 & 90 & $\ldots$ & 20 & 20 & 20 & 20 \\
\hline Rathayibacter tritici NCPPB 1953 & 12 & 78 & 78 & 78 & 78 & 78 & 78 & 78 & 78 & 78 & 78 & 78 & $\ldots$ & 20 & 19 & 20 \\
\hline Leifsonia xyli CTCB07 & 13 & 78 & 78 & 78 & 78 & 78 & 78 & 78 & 78 & 78 & 78 & 78 & 79 & $\ldots$ & 20 & 21 \\
\hline Clavibacter sepedonicus ATCC $33113^{\mathrm{T}}$ & 14 & 78 & 78 & 78 & 78 & 78 & 78 & 78 & 78 & 78 & 78 & 78 & 78 & 78 & $\ldots$ & 46 \\
\hline Clavibacter michiganensis $\mathrm{NCPPB} 382^{\mathrm{T}}$ & 15 & 78 & 78 & 78 & 78 & 78 & 78 & 78 & 78 & 78 & 78 & 78 & 78 & 79 & 92 & $\ldots$ \\
\hline
\end{tabular}

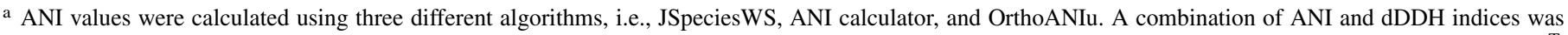
used to designate a taxonomic status to a given phylogenetic clade. Among the Curtobacterium spp. genome sequences only the strains P990, CFBP $3418^{\mathrm{T}}$, MMLR14-002, and MMLR14-014 belong to C. flaccumfaciens sensu stricto.

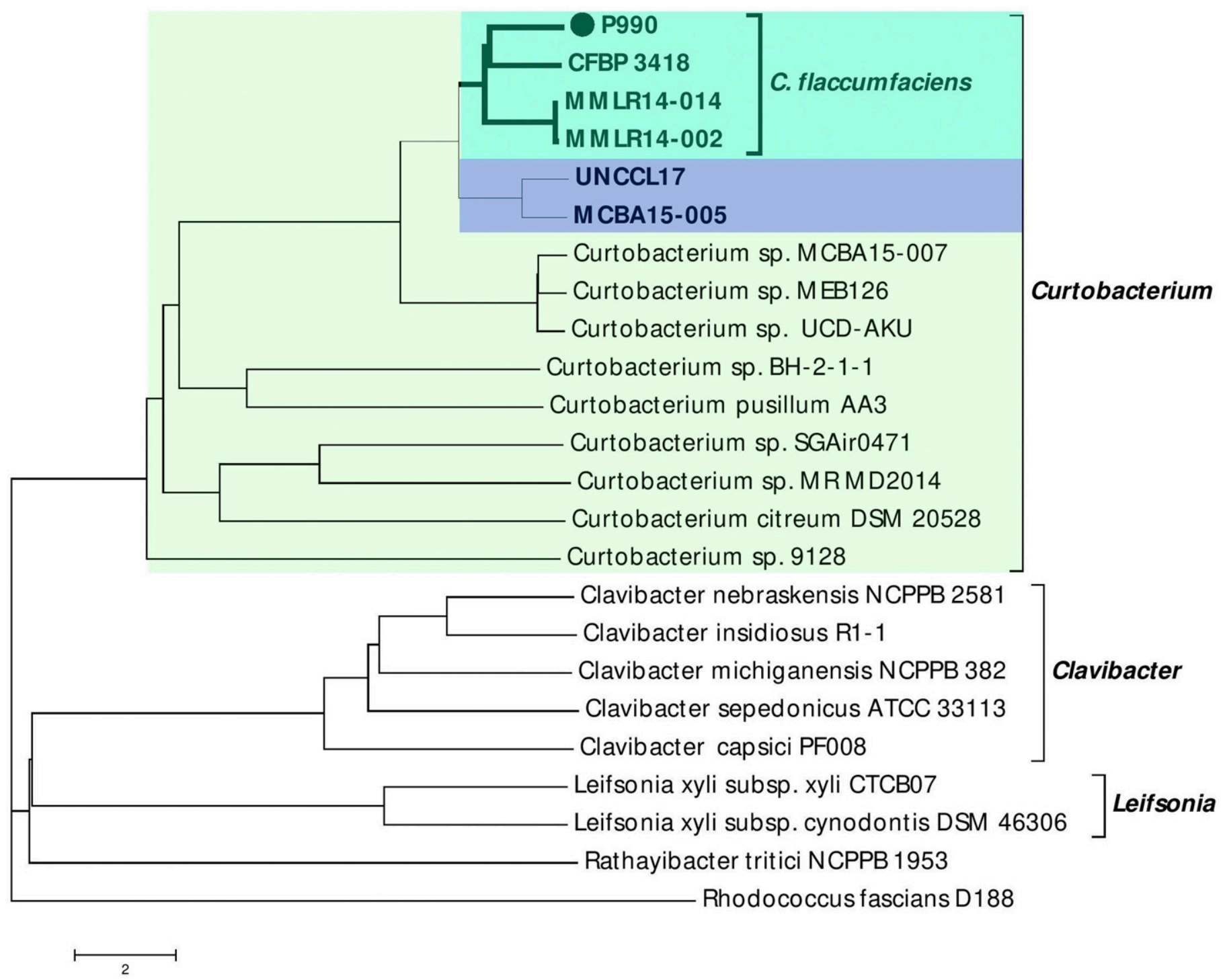

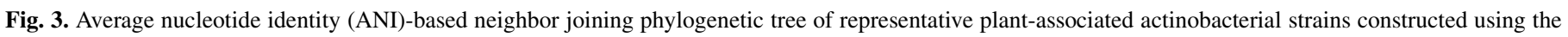

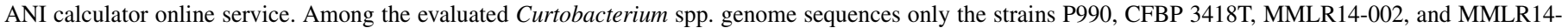
014 belong to $C$. flaccumfaciens sensu stricto, while the two strains UNCCL17 and MCBA15-005 are more likely to belong to a novel species. 
and overall wilt symptoms were observed on common bean, cowpea, and mung bean plants (Supplementary Fig. S1a). Symptoms on soybean plants were observed later than those on the other crops (i.e., at $15 \mathrm{dpi}$ ) and included necrotic lesions (tan spot) on the leaves surrounded by a faint yellow halo at the edges of the necrotic areas. The inoculated P990 strain was consistently reisolated from the symptomatic plants and its identity was confirmed using the primer pair CffFOR2/CffREV4 (data not shown). On the other hand, dipping the common bean seedlings into different concentrations of cell-free culture filtrate of the strain P990 resulted in wilting and plant death at 2 to 4 dpi depending on the concentration of the culture filtrate, where the more concentrated the culture filtrate was the earlier wilting symptoms were observed (Supplementary Fig. S1b). Attempts to isolate the bacterial wilt pathogen from the symptomatic seedlings inoculated with culture filtrate were unsuccessful, indicating the absence of viable $C$. flaccumfaciens pv. flaccumfaciens cells in the symptomatic tissues. Hence, it could be hypothesized that a toxic compound is responsible for the development of wilt symptoms. Control seedlings dipped into sterile water as well as those seedlings dipped into $C$. flaccumfaciens pv. flaccumfaciens-free LB medium remained healthy up to $5 \mathrm{dpi}$.

General feature of $\mathbf{P 9 9 0}$ genome. The complete genome sequence of P990 was constructed by employing Oxford Nanopore technology and subsequent de novo genome assembly using Flye online service. P990 has a single circular chromosome consisting of $3,736,959$ bp. The GC content of the chromosome is $71.0 \%$. Figure 1A represents the circular diagram and genome features of the P990 chromosome. From the outermost to inner circles, nucleotide numbering (circle 1), COG annotation of forward (circle 2) and reverse (circle 3) strands, noncoding RNAs (rRNA red, tRNA blue, sRNA green; circle 4), GC content (circle 5), and GC skew (circle 6). No significant GC skew was detected in the P990 chromosome, which was in congruence with the results reported for other plant pathogenic actinobacteria (Gartemann et al. 2008). The chromosome of P990 contains a total of 3,672 predicted CDSs. Based on the results obtained from the NCBI prokaryotic genome annotation pipeline, 3,586 CDSs were capable of coding a protein. Among the predicted CDSs, 710 were assigned as hypothetical proteins. A total of 59 RNA genes were detected with 48 tRNAs,

TABLE 3. Genomic characteristics of plant-associated actinobacterial strains used in this study ${ }^{\mathrm{a}}$

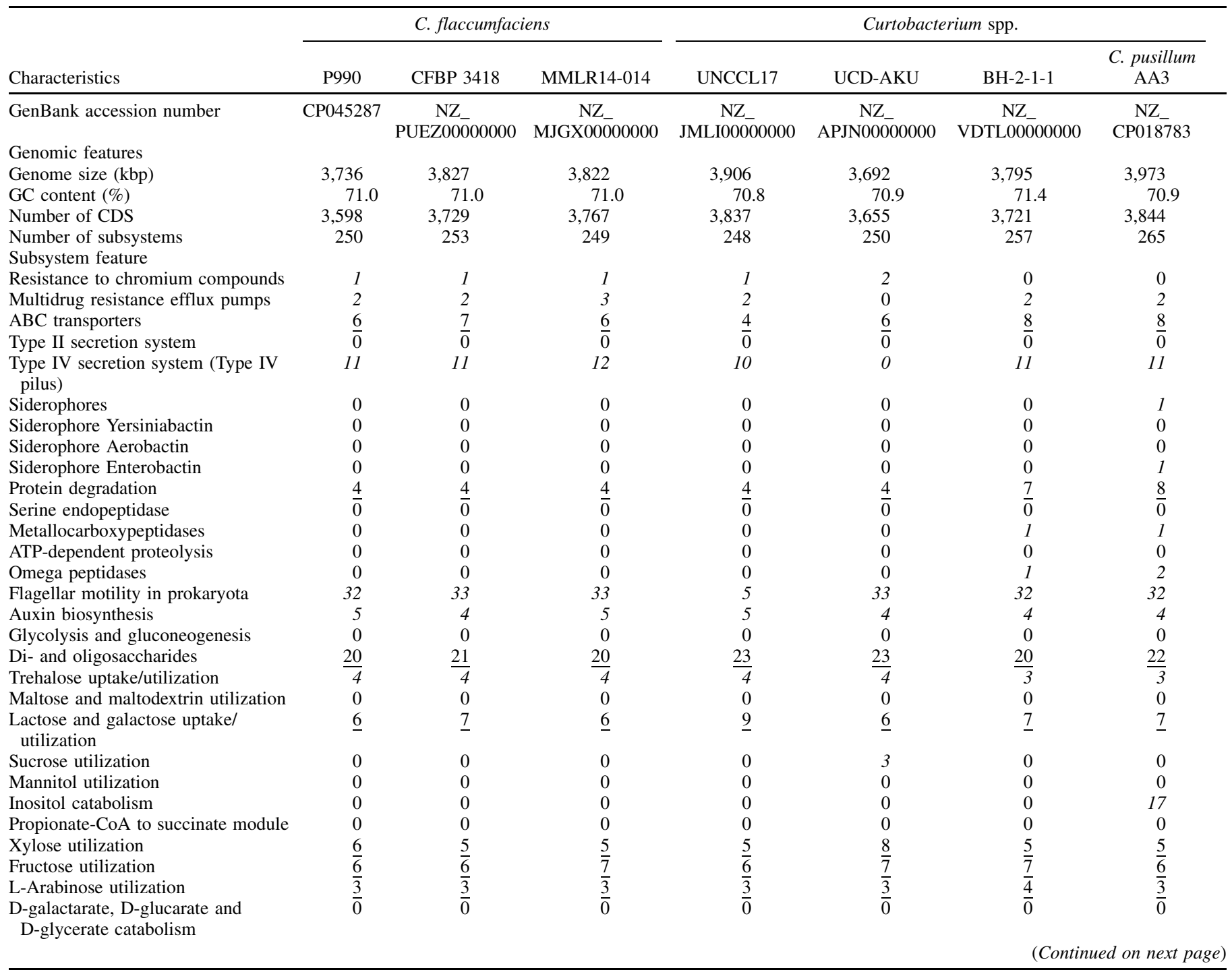

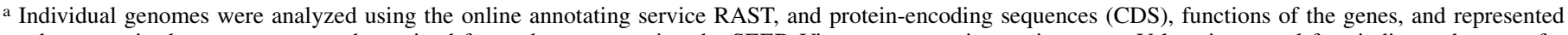
subsystems in the genomes were determined for each genome using the SEED-Viewer comparative environment. Values in normal font indicate absence of a given subsystem, italicized values indicate presence of a given subsystem, underlined values indicate low number of subsystems, and bold values indicate high number of subsystems. 
eight rRNAs, and three ncRNAs. Furthermore, 70 pseudogenes were detected within the genome, among which 40 were incomplete CDSs, 34 were frameshifted, 12 had multiple problems, and nine pseudogenes had internal stop. Supplementary Figure S2 summarizes the functional classification of gene clusters and orthologous groups resulted from the online services CAZy (A), COG (B), eggNOG (C), GO (D), and KEGG (E). As shown in Supplementary Figure S3a, the genomic content of $\mathrm{P} 990$ had the highest similarity to Curtobacterium sp. UNCCL17 (NZ_JMLI00000000.1).

Plasmids. The genome of P990 contains a 147,310-bp circular plasmid (pCff1) with $66.1 \% \mathrm{G}+\mathrm{C}$ content. In addition, two smaller plasmid-like circular DNAs, pCff2 (25,142 bp) and pCff3 $(22,293 \mathrm{bp})$, were detected within the genomic contents of the bacterium. Although pCff1 had a set of well-organized proteincoding genes, there was no predicted open reading frames on plasmid-like circular DNAs designated as pCff2 and pCff3; hence, they were excluded from our analyses. Figure 1B shows the circular diagram and features of pCff1 in P990. Data mining among various public databases revealed that homologs of endo-1, 4-betaglucanase (celA; two copies) in Aspergillus oryzae (yellow koji mold), which is responsible for cellulose hydrolysis, was found in pCff1. Further, homologs of $\operatorname{chpC}$ gene (in two copies) and a putative extracellular serine protease (ppaJ) in Clavibacter michiganensis were found in pCff1 (locus tag: pCM1_0023). Investigation of CAZy database showed that there were one carbohydrate-binding module, three glycoside hydrolases, and one polysaccharide lyase in pCff1 (Supplementary Fig. S4a). Further, investigation in COG and eggNOG databases confirmed the presence of at least $10 \mathrm{CDSs}$ in pCff1 contributing to carbohydrate transport and metabolism (Supplementary Fig. S4b and c). A summary of function specification of pCff1 CDSs using different databases is shown in Supplementary Figure S4. Interestingly, $18.3 \%$ of the genomic contents of pCff 1 had similarity to Clavibacter michiganensis, while $15.6 \%$ of the contents of the plasmid was similar to Xanthomonas translucens (Supplementary Fig. S3b).

Genomic islands. The online service IslandViewer has identified 24 GIs on the chromosome of P990 within the range of 4,051 bp (GI-V) and 17,787 bp (GI-X). Interestingly, 12 out of 24 GIs had $<70 \% \mathrm{G}+\mathrm{C} \%$ content as listed in Table 1. BLASTx-based screening of the GIs revealed that 18 GIs were $C$. flaccumfaciens pv.

TABLE 3. (Continued from previous page)

\begin{tabular}{|c|c|c|c|c|c|c|}
\hline \multicolumn{5}{|c|}{ Clavibacter spp. } & \multirow[b]{2}{*}{$\begin{array}{l}\text { Rathayibacter tritici } \\
\text { NCPPB } 1953\end{array}$} & \multirow[b]{2}{*}{$\begin{array}{c}\text { Leifsonia xyli subsp } \\
\text { xyli CTCB07 }\end{array}$} \\
\hline $\begin{array}{l}\text { C. michiganensis } \\
\text { NCPPB } 382\end{array}$ & $\begin{array}{l}\text { C. capsici } \\
\text { PF008 }\end{array}$ & $\begin{array}{l}\text { C. nebraskensis } \\
\text { NCPPB } 2581\end{array}$ & $\begin{array}{l}\text { C. sepedonicus } \\
\text { ATCC } 33113\end{array}$ & $\begin{array}{l}\text { C. michiganensis subsp. } \\
\text { phaseoli CFBP } 8627\end{array}$ & & \\
\hline AM711867 & $\frac{\mathrm{NZ}_{-}}{\mathrm{CP} 012573}$ & NC_020891 & NC_010407 & QWGV00000000 & NZ_CP015515 & AE016822 \\
\hline 3,297 & 3,056 & 3,063 & 3,258 & 3,052 & 3,354 & 2,584 \\
\hline 72.7 & 73.6 & 73.0 & 72.6 & 73.5 & 69.5 & 67.7 \\
\hline 2,979 & 2,725 & 2,739 & 3,047 & 2,642 & 3,289 & 2,858 \\
\hline 345 & 326 & 325 & 345 & 315 & 241 & 236 \\
\hline 0 & 0 & 0 & 0 & 0 & 0 & 0 \\
\hline 0 & 0 & 0 & 0 & 0 & 0 & 0 \\
\hline 37 & 26 & 32 & 33 & 40 & 0 & 2 \\
\hline 3 & 3 & 3 & 3 & 3 & 0 & $\overline{0}$ \\
\hline 0 & 0 & 0 & 0 & 0 & 0 & 0 \\
\hline 5 & 3 & 5 & 3 & 3 & 0 & 0 \\
\hline 2 & 0 & 2 & 0 & 0 & 0 & 0 \\
\hline 3 & 3 & 3 & 3 & 3 & 0 & 0 \\
\hline 0 & 0 & 0 & 0 & 0 & 0 & 0 \\
\hline 21 & 21 & 19 & 19 & 22 & 5 & 9 \\
\hline 1 & 1 & 1 & 1 & 1 & $\overline{0}$ & $\overline{0}$ \\
\hline 3 & 3 & 3 & 3 & 3 & 2 & 3 \\
\hline 9 & 9 & 8 & 9 & 9 & 0 & 0 \\
\hline 2 & 2 & 2 & 1 & 3 & 0 & 1 \\
\hline 0 & 0 & 0 & 0 & 0 & 0 & 5 \\
\hline 0 & 0 & 0 & 0 & 0 & 0 & 0 \\
\hline 13 & 13 & 12 & 13 & 12 & 0 & 0 \\
\hline 49 & 38 & 40 & 46 & 44 & 22 & 13 \\
\hline 0 & 0 & 0 & 0 & 0 & $\frac{-2}{4}$ & $\frac{1}{0}$ \\
\hline 11 & 12 & 10 & 10 & 16 & 0 & 0 \\
\hline 16 & 12 & 12 & 15 & 14 & $\underline{4}$ & $\underline{6}$ \\
\hline 3 & 0 & 2 & 2 & 0 & 4 & 0 \\
\hline 7 & 7 & 7 & 6 & 5 & 0 & 0 \\
\hline 16 & 15 & 14 & 0 & 14 & 0 & 8 \\
\hline 5 & 5 & 6 & 5 & 5 & 5 & 6 \\
\hline 18 & 10 & 11 & 15 & 7 & 5 & 2 \\
\hline 13 & 11 & 11 & 11 & $1 \frac{1}{2}$ & $1 \overline{0}$ & $\frac{5}{6}$ \\
\hline 12 & 12 & 11 & 12 & 11 & 4 & $\overline{0}$ \\
\hline 5 & 0 & 0 & 4 & 0 & $\overline{0}$ & 0 \\
\hline
\end{tabular}


flaccumfaciens-specific, in which $>70 \%$ of the nucleotide content did not occur in the nonpathogenic Curtobacterium spp. strains, while the remaining six GIs were detected either in Curtobacterium spp. or C. flaccumfaciens (Table 1). The largest of these GIs $(17,787 \mathrm{bp})$ is located between the positions 1,604,094 and $1,621,881$ bp of the P990 genome (Fig. 2A). Results of gene predictions for each of these GIs are shown in Table 1. A number of biological functions could be assigned to each of the individual GIs. For instance, proteins predicted in GI-I were responsible for different steps of riboflavin biosynthesis. Further, several DUF (domain of unknown function) families were identified among different GIs. In GI-II no known protein product was identified thus all the CDSs were designated as hypothetical proteins. In order to determine the status of these GIs in the genomes of other nonpathogenic Curtobacterium spp. strains as well as the other actinobacterial plant pathogens, BRIG 0.95 was used to whole genome-based comparisons with P990 as the reference genome. Most of the detected GIs were $C$. flaccumfaciens pv. flaccumfaciensspecific as shown on the comparative circular map of nine actinobacterial strains (Fig. 2B). For instance, the GIs II, IV, VI, VIII-X, XII-XV, and XX-XXIII could be visually determined as C. flaccumfaciens pv. flaccumfaciens-specific. On the other hand, four GIs were detected on pCff1 as listed in Table 1. Interestingly, a number of putative virulence-associated genes, i.e., pectate lyase (protein id: QFS80865.3), S1 family peptidase (serine protease; protein ids: QIH95653.1, QIH95654.1, and QFS80891.2), and glycosyl hydrolase family (protein id: QFS80892.1), were detected on GIs of pCff1.

Phylogenetic analyses. ANI calculator online service was used to conduct a phylogenetic analysis among the genome sequences of all 45 available actinobacterial strains in the NCBI GenBank database designated as Curtobacterium spp. Neighbor joining phylogenetic tree constructed with all-versus-all strategy revealed high genetic diversity among these strains (Supplementary Fig. S5). ANI values between different pairs of strains varied from 75 to $99 \%$ among Curtobacterium spp. (data not shown). The genome of P990 shared ANI and dDDH values of 97 and 74\%, respectively, with the pathotype strain of the pathogen CFBP $3418^{\mathrm{T}}$, confirming the taxonomic position of the strain as reported previously (Table 2). Using the standard criteria based on ANI and dDDH (Kim et al. 2014), it has been shown that among the 45 evaluated Curtobacterium spp. genome sequences only the strains P990, CFBP 3418 ${ }^{\mathrm{T}}$, MMLR14-002, and MMLR14-014 belong to C. flaccumfaciens sensu stricto, while the two strains UNCCL17 with an unknown source and MCBA15-005 isolated from leaf litter were phylogenetically closely related to $C$. flaccumfaciens but more likely to belong to a novel species (Fig. 3; Table 2). The C. flaccumfaciens sensu stricto strains were clustered in a monophyletic clade showing 97\% ANI with one another. Apart from the strains UNCCL17 and MCBA15-005, the closest clade to C. flaccumfaciens consisted of three strains, i.e., MCBA15-007, MEB126, and UCD-AKU, isolated from leaf litter, Arabidopsis thaliana leaf, and residential carpet, respectively.

Comparative genomics. Comparative genomics using the data provided by RAST and SEED viewer online services revealed that the genome size among plant-associated actinobacteria included in this study varied between 2,584 kbp in L. xyli subsp. xyli and 3,906 kbp in Curtobacterium sp. UNCCL17, with the G+C\% content varying between $67.7 \%$ in L. xyli subsp. xyli and $73.6 \%$ in Clavibacter capsici $\mathrm{PF} 008^{\mathrm{T}}$ (Table 3). Furthermore, the number of CDSs varied between 2,642 in Clavibacter michiganensis subsp. phaseoli CFBP $8627^{\mathrm{T}}$ and 3,844 in Curtobacterium pusillum AA3. Table 3 presents comparative genomics of $\mathrm{P} 990$ against a panel of 13 representative plant-associated actinobacterial strains.

Several lines of evidence highlight differences in metabolic networks and subsystem profiles between $C$. flaccumfaciens pv. flaccumfaciens and those of nonpathogenic Curtobacterium spp. strains, as well as the other Gram-positive bacterial plant pathogens.
For instance, subsystems that are responsible for resistance to antibiotics and toxic compounds, motility and chemotaxis, type IV secretion system, auxin biosynthesis, and trehalose uptake/ utilization were found in Curtobacterium spp. strains but not in the other actinobacterial plant pathogens (Table 3). The exceptions were L. xyli subsp. xyli CTCB07 and Rathayibacter tritici NCPPB 1953 in which the motility and chemotaxis, and trehalose uptake/ utilization subsystems were found, respectively. In contrast, with some exceptions (as detailed in Table 3) type II secretion system, different types of siderophores, serine endopeptidase, metallocarboxypeptidases, ATP-dependent proteolysis, omega peptidases, glycolysis and gluconeogenesis, maltose and maltodextrin utilization, sucrose utilization, mannitol utilization, inositol catabolism, propionate-CoA to succinate module, as well as Dgalactarate, D-glucarate, and D-glycerate catabolism were found in Clavibacter spp., Rathayibacter sp., and Leifsonia sp. plant pathogens but not in Curtobacterium spp. strains.

Surprisingly, the FHIPEP (flagellar/Hr/invasion proteins export pore) family type III secretion system (T3SS, protein id: QHN63420.1) was detected in the genome of P990, which was absent in Clavibacter spp. and Rathayibacter sp. while present in Leifsonia sp. strains. Furthermore, a nonflagellar EscU/YscU/HrcU family T3SS export apparatus switch protein (protein id: QFS80385.2) and the flagellar T3SS pore gene (fliP, protein id: QFS80387.1) were detected in the genome of P990, which were absent in the other plant pathogenic actinobacteria i.e., Clavibacter spp. and Rathayibacter sp. As for the type IV secretion system components, type IV secretion proteins (Rhs, protein ids: QHN62613.1 and QFS80419.2), type IV pilus assembly protein (PilM, protein id: QHN62675.1), as well as type IV pilus twitching motility protein (PilT, protein id: QHN63630.1) were detected in the genome of P990 which were absent in the other actinobacteria evaluated in Table 3.

BLASTx was performed to evaluate the presence of virulenceassociated genes in different plant pathogenic Clavibacter strains in the genome of P990. Homologous of virulence-associated genes 1,4-beta-xylanase ( $x y s A$, protein id: QHN62540.1), pectate lyase (pelA1 and pelA2), serine protease ( $\operatorname{chp} C, \operatorname{chp} G$, and pat-1), as well as sortase (srtA) in the tomato pathogen Clavibacter michiganensis NCPPB 382T were detected in the chromosome and plasmid pCff 1 of P990. Three genes, i.e., 1,4-beta-xylanase (protein id: QHN62540.1), trypsin-like serine protease (protein id: QHN63486.1), and sortase (protein id: QFS79737.2), were found on chromosome, while pectate lyase (protein ids: QFS80865 and QFS80866) and trypsin-like serine protease (protein id: QFS80891) were detected on plasmid pCff1.

Orthologous gene clusters were determined using OrthoVenn online service through five-versus-five designations of the representative strains from different sets of actinobacteria (Fig. 4A and B). Curtobacterium spp. strains included in the OrthoVenn analyses shared 1,711 proteins in their genome sequences (Fig. 4A). The C. flaccumfaciens pv. flaccumfaciens strains P990 and CFBP 3418T showed one and seven unique proteins, respectively, in their sequences, while 26 proteins were shared between these two strains. Furthermore, 30 proteins were shared among the three $C$. flaccumfaciens strains, i.e., P990, CFBP 3418T, and MMLR14-014. The higher number of unique proteins in CFBP 3418T in comparison with P990 was likely due to the sequencing and assembling technology of CFBP 3418T where the chromosomal DNA and hypothetical plasmid(s)s were assembled in the same file. On the other hand, the strain $\mathrm{P} 990$ had 43 unique protein in the OrthoVenn analyses in comparison with four non-Curtobacterium actinobacterial species, while 1,026 proteins were shared among these six plant pathogens (Fig. 4B). Among the non-Curtobacterium actinobacterial strains, P990 had the highest number of shared proteins (122) with $R$. tritici NCPPB 1953.

One-versus-all collinearity test of P990 genome against a set of four Curtobacterium spp. strains was conducted using Mauve. The organization of locally collinear blocks (LCBs) was visualized to determine genome rearrangements and segmentation. To provide a 
precise scheme from the collinearity of the genomes, LCB weight of all the alignments was adjusted to 150 . The order of the LCBs in P990 was generally in congruence with the LCBs in CFBP 3418T; however, the latter strain has a reversion in almost $70 \%$ of the genome content (nucleotides 1 to $2,700 \mathrm{kbp}$ ). The majority of the LCBs were present in all the five Curtobacterium sp. strains indicating that the gene content within the evaluated strains is preserved (Fig. 5A). Among the three $C$. flaccumfaciens strains, alignment of the chromosome was broken down into several LCBs in the strain MMLR14-014, indicating multiple translocations and inversions in comparison with the genome of CFBP 3418T. As for the two Curtobacterium sp. strains UNCCL17 and MCBA15-007, the number of LCBs in the strain UNCCL17 was much less than those in the strain MCBA15-007, which was in congruence with their respective phylogenetic distance from the reference strain P990 (Fig. 3). Considering the collinearity of the genome of $P 990$ against four actinobacteria (Fig. 5B), only small portions of the LCBs in the P990 genome were preserved within the actinobacterial plant pathogens indicating significant rearrangements and insertion/deletions between P990 and those of four actinobacterial species.

No integrative plasmid (episome) and prophage were detected using the PlasmidFinder and PHASTER online services, respectively, in the genome sequence of P990. Furthermore, no acquired antimicrobial resistance gene was found using the ResFinder server. In silico screening for bacteriocins and antibiotic peptides showed that P990 is capable of producing linocin_M18 and linaridin. Although linocin_M18 was detected in the genome sequences of CFBP $3418^{\mathrm{T}}$, UNCCL17, and MCBA15-005, linaridin was shown to be unique for P990 among the strains investigated in Figure 3. The C. flaccumfaciens strains MMLR14_002 and MMLR14_014 as well as the Curtobacterium sp. strain MCBA15_ 005 contained only sactipeptides, while the strain UNCCL17 produced cypemycin in addition to linocin_M18 and sactipeptides. No evidence was found for the presence of bacteriocins in the strains BH-2-1-1 and SGAir0471, while in the strains MCBA15-007, MEB126, UCD-AKU, and C. pusillum AA3 putative bacteriocins with unknown identity were detected (data not shown). The bacteriocins lactococcin_972 and zoocin_A were detected only in the Curtobacterium sp. strains MR-MD2014, DSM 20528, and 9128, which were phylogenetically far from the plant pathogenic members of the genus, indicating distinctive differences in the bacteriocins scheme of the strains designated as $C$. flaccumfaciens.

\section{DISCUSSION}

Among the economically important Gram-positive bacterial plant pathogens, $C$. flaccumfaciens pv. flaccumfaciens is the least studied member with no information from the virulence repertoires and pathogenicity determinates. In this study, we provide the first complete genome sequence of the C. flaccumfaciens pv. flaccumfaciens strain P990 causing bacterial wilt on dry beans. The bacterium contains a circular chromosome $(3,736 \mathrm{kbp})$ as well as a circular plasmid pCff1 (147 kbp) both carrying a number of virulence-associated genes, e.g., 1,4-beta-xylanase ( $x y s A)$, pectate lyase (pelA1 and pelA2), serine protease ( $\operatorname{chpC}, \operatorname{chpG}$, and pat-1), and sortase $(s r t A)$. Furthermore, evidences for the production of toxic compounds and bacteriocins were detected using both phenotypic tests (culture filtrate assay) and genomics investigations.

Concerning the plasmid repertories of P990, results obtained in this study were incongruent with those of previously reported data. Indeed, agarose gel-based plasmid profiling using different strains of $C$. flaccumfaciens pv. flaccumfaciens did not find any evidence for the presence of plasmids (Gross et al. 1979; Osdaghi et al. 2018a), while genome sequencing in this study revealed the presence of at least one circular plasmid (pCff1) as well as two plasmid-like DNAs, with sizes of 25 and $22 \mathrm{kbp}$, in the genome of P990. Differences between the in vitro and in silico results might be due to the low number of plasmid copies in C. flaccumfaciens pv. flaccumfaciens cells leading to their undetectability using agarose gel-based techniques. Further investigations, e.g., plasmid curing and targeted mutagenesis are warranted to decipher the role of plasmid(s) in the biology of bacterial wilt pathogen. Meanwhile, detection of virulence-associated genes, i.e., pectate lyase, endo1,4-beta-glucanase, and serine protease, in the pCff1 DNA sequence
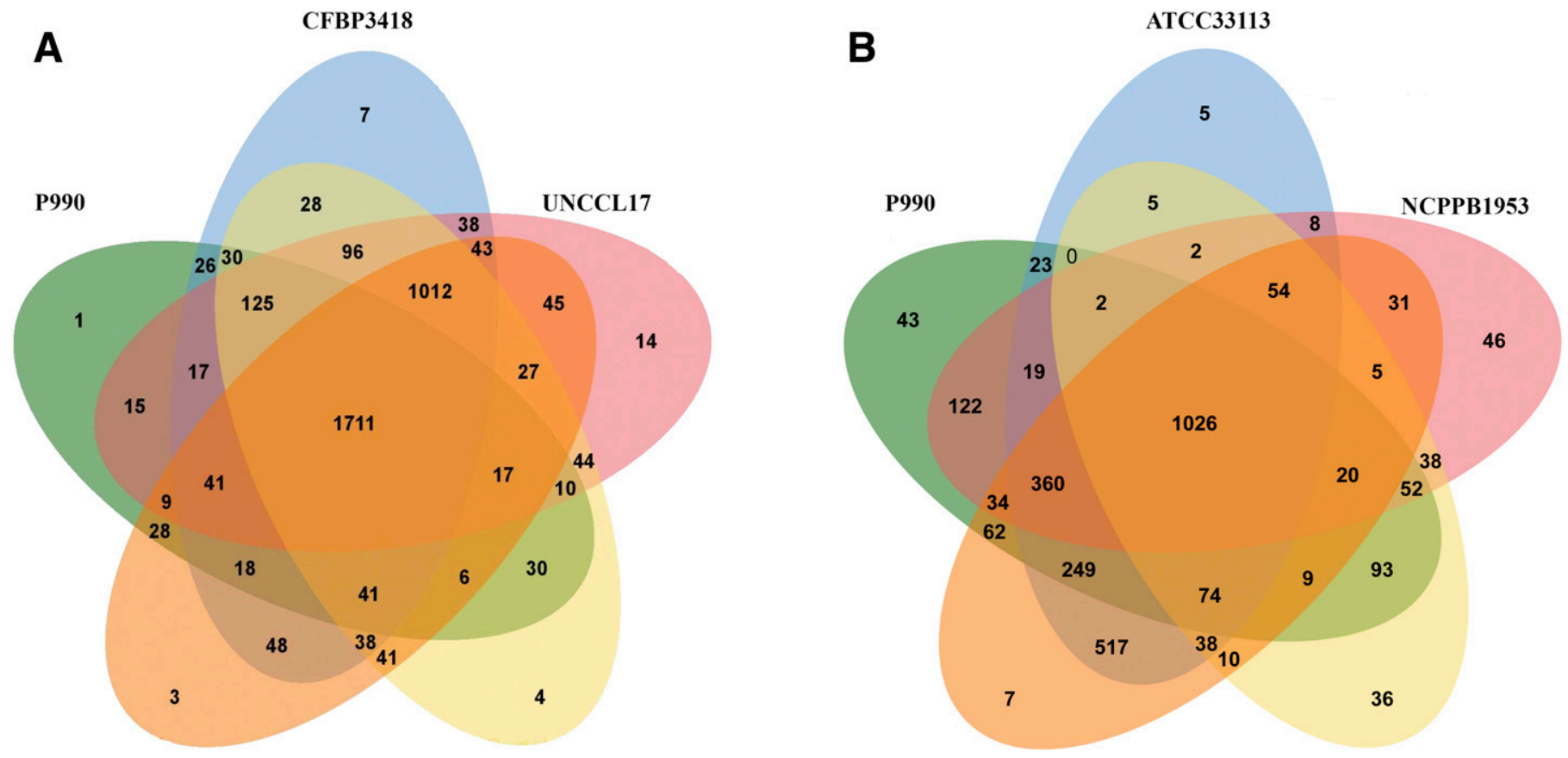

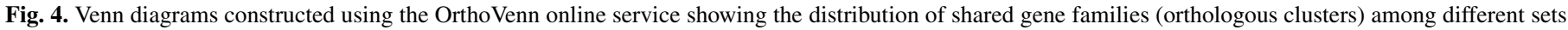
of strains, i.e., A, Curtobacterium spp. strains and $\mathbf{B}$, plant-associated actinobacterial strains. 
suggests the putative role of plasmids in the pathogenicity of C. flaccumfaciens pv. flaccumfaciens. In addition, it has been shown that a plasmid determines resistance to arsenate, arsenite, and antimony (III) in C. flaccumfaciens pv. oortii (Hendrick et al. 1984). Although no morphological difference was found between beanpathogenic and nonpathogenic $C$. flaccumfaciens strains, the former were resistant to different concentrations of arsenic, while the latter were sensitive to the same concentrations (Osdaghi et al. 2018a). Interestingly, two arsenic transporter genes (protein ids: QHN62312.1 and QFS79252.1) and an arsenate reductase (ArsC, protein ids: QFS79253.1 and QFS80476.1) were detected in the chromosomal genome of P990. It remains undetermined whether the resistance against arsenic is mediated by the detected plasmids in C. flaccumfaciens pv. flaccumfaciens strains similar to those described for other bacterial species (Silver and Misra 1988). Furthermore, homologs of copper resistance protein (CopC, protein ids: QFS78994.1, QFS79968.2, and QFS80310.2), copper homeostasis protein (CutC, protein id: QHN62860.1), and copper resistance protein D (pcoD, protein ids: QFS79544.1 and QHN62928.1) were identified in the genome of P990. All these genes are involved in copper resistance, which may explain why copper-based chemicals are ineffective in field control of the bacterial wilt pathogen (Lamichhane et al. 2018; Osdaghi et al. 2020a).

So far, the lack of publicly available $C$. flaccumfaciens pv. flaccumfaciens complete genome sequence was limiting our understanding of its virulence mechanisms and pathogenicity determinants. On the other hand, genetic manipulation technologies and transformation vectors have not yet been developed for the bacterium, although it may be possible to use the platforms of the closely related pathogens Clavibacter michiganensis and L. xyli subsp. xyli (Brumbley et al. 2006; Thapa et al. 2019). Similar to its actinobacterial relatives, $C$. flaccumfaciens pv. flaccumfaciens colonizes the xylem system of the host plant and moves endophytically (Thapa et al. 2019; Zaumeyer 1932). Due to the lack of T3SS in actinobacterial plant pathogens, they use a set of lytic enzymes, toxins, and hormones to disrupt host plant cell walls and acquire
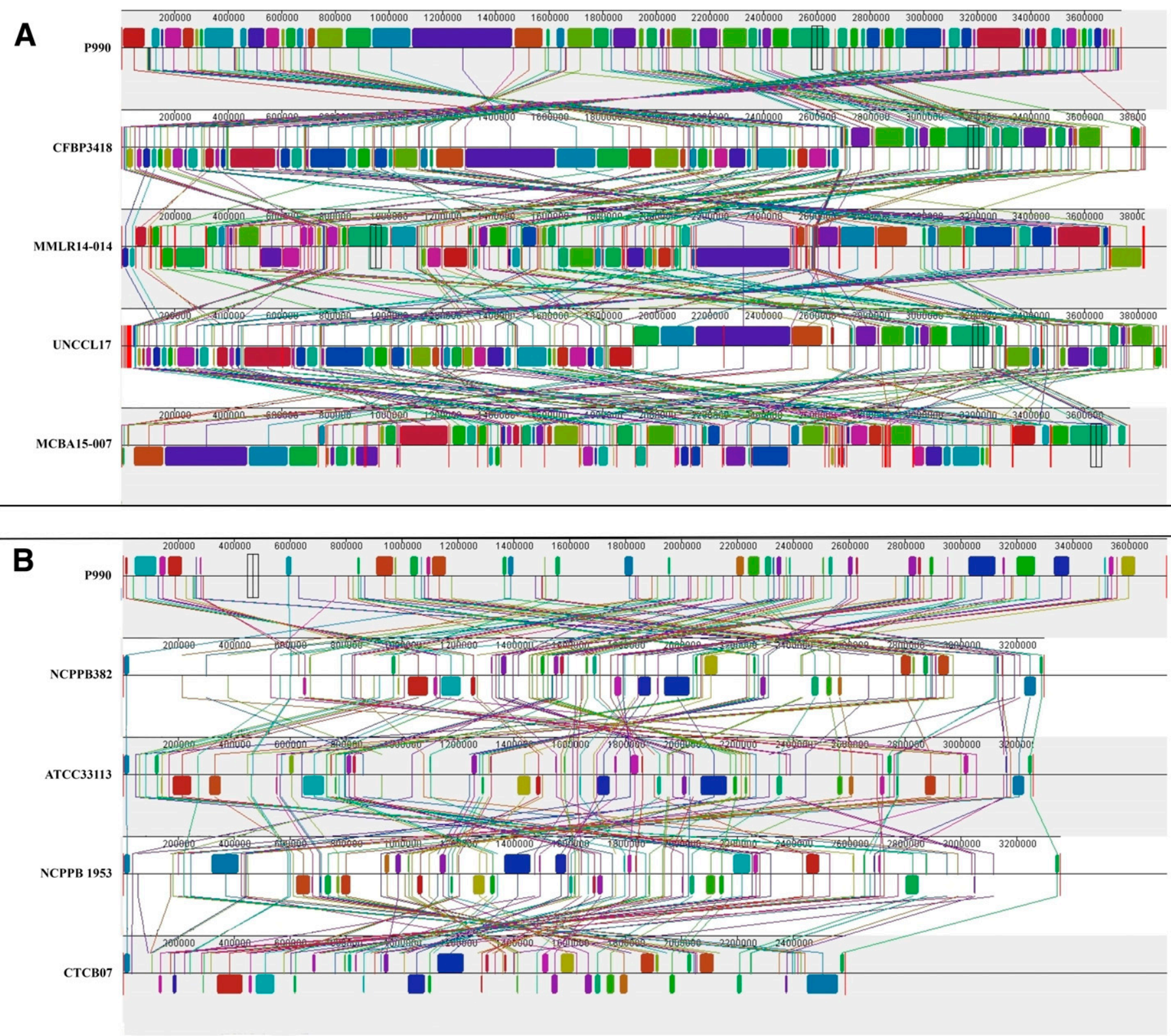

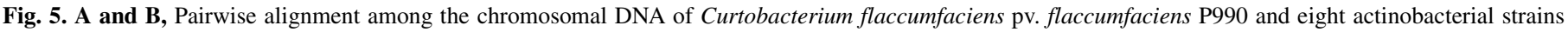

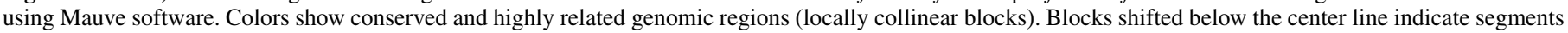

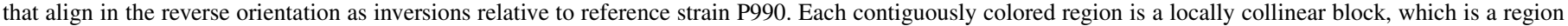
without rearrangement of homologous backbone sequence. Lines between two genomes trace each orthologous locally collinear block. 
nutrients (Thapa et al. 2019). Interestingly, we found a number of T3SS's components, i.e., FHIPEP family T3SS, EscU/YscU/HrcU family T3SS export apparatus switch protein and flagellar T3SS pore gene $f l i P$ in the genome of P990. Since phenotypic feature reflecting the activity of T3SS, e.g., hypersensitivity reaction, has not been reported in $C$. flaccumfaciens pv. flaccumfaciens, the functionality and contribution of the above-mentioned T3SS components to the virulence of the pathogen need to be evaluated.

Vidaver (1982) has noted damage to xylem and decomposition of middle lamella of $C$. flaccumfaciens pv. flaccumfaciens-infected plants prior to wilting. Furthermore, high molecular weight glycopeptides were isolated from the pathogen, some of which were considered to cause plant cell wall disruption (Schuster and Coyne 1981). De Bruyne et al. (1992) showed that $C$. flaccumfaciens pv. flaccumfaciens harbors lytic enzymes, e.g., $\beta$-glucosidase, esterase, peptidases, and lipases, all of which have similarity to Clavibacter michiganense genes. Detection of virulence-associated genes 1,4-beta-xylanase ( $x y s A)$, pectate lyase (pelA1 and pelA2), serine protease $(\operatorname{chp} C, \operatorname{chp} G$, and pat-1), and sortase $(\operatorname{srt} A)$ in the chromosome and plasmid pCff1 of $\mathrm{P} 990$, which were homologous to the corresponding genes in tomato pathogen Clavibacter michiganensis NCPPB $382^{\mathrm{T}}$, confirms the activity of cell wall degrading enzymes in $C$. flaccumfaciens pv. flaccumfaciens and suggests the putative role of these genes in the pathogenicity of the bacterium. Histological studies have also confirmed enzymatic activities in the C. flaccumfaciens pv. flaccumfaciens-infected tissues of dry beans (Nelson and Dickey 1970; Vidaver 1982).

Furthermore, it has been hypothesized that the mechanism of wilting in C. flaccumfaciens pv. flaccumfaciens is the restriction of water movement in xylem by phytotoxic glycopeptides (Gross and Vidaver 1979; Schuster and Coyne 1981). In this study, we found that a cell-free culture filtrate of P990 was capable of inducing wilting on common bean which is in congruence with the hypothesis that a toxic compound is responsible for virulence of the pathogen. Wood and Easdown (1990) have also reported a temperature-resistant substrate derived from the culture filtrate of C. flaccumfaciens pv. flaccumfaciens strains isolated in Australia that induced wilting symptoms on mung bean. However, the biological characteristics of the phytotoxic compounds produced by $C$. flaccumfaciens pv. flaccumfaciens remain undetermined. In vitro investigations suggest the production of bacteriocins in C. flaccumfaciens pv. flaccumfaciens similar to those reported in the other actinobacterial pathogens (Durbin 1972). Gross et al. (1979) investigated the biological features of bacteriocins produced by 10 C. flaccumfaciens pv. flaccumfaciens strains and named the resulting substrates as "flaccumfacin". Similarly, genomics investigation confirmed the presence of linocin_M18 and linaridin bacteriocins in the genome of P990. Linocin_M18 is a bacteriocin of Brevibacterium linens M18 that inhibits the growth of several coryneform and other Gram-positive bacteria (Valdés-Stauber and Scherer 1994). It has been shown that the ability of C. flaccumfaciens pv. flaccumfaciens strains to produce bacteriocins against the pathogenic and nonpathogenic actinobacterial strains positively correlated with the virulence vigor and aggressiveness of the same strain on common bean. For instance, among 45 Iranian $C$. flaccumfaciens pv. flaccumfaciens strains, P990 had the most vigorous suppressive effect on the bacterial species evaluated through bacteriocin production test, while the same strain had the most aggressiveness on common bean, and the most fluidal colonies on culture media at $27^{\circ} \mathrm{C}$ (Osdaghi et al. 2018c).

Following the development of high throughput molecularphylogenetic techniques, taxonomy of plant pathogenic actinobacteria which have previously been relied on phenotypic features was reconsidered (Li et al. 2018; Osdaghi et al. 2020b). In this study, ANI- and dDDH-based phylogenetic analyses revealed that the genetic diversity within the bacterial strains designated as C. flaccumfaciens in the literature is higher than that has so far been described. Only two strains, MMLR14-002 and MMLR14014, were identified as members of $C$. flaccumfaciens while the remaining strains need to be reclassified as novel taxa. Recently, multilocus sequence analysis using the sequences of five housekeeping genes (i.e., atpD, gyrB, ppk, recA, and $r p o B$ ) revealed that the three strains MCBA15-007, MEB126, and UCD-AKU are phylogenetically closely related to the type strain of poinsettia (Euphorbia pulcherrima) pathogen C. flaccumfaciens pv. poinsettiae ICMP 2566T, while the strains MCBA15-005 and UNCCL17 are phylogenetically closely related to the type strain of sugar beet pathogen C. flaccumfaciens pv. betae ICMP 2594T (Osdaghi et al. 2018a). This indicates that the plant pathogenic members of C. flaccumfaciens are less likely to belong to the same species, reinforcing the need to a reconsideration in the taxonomy of phytopathogenic members of the species. A formal taxonomic study would provide appropriate nomenclature for these taxa.

In conclusion, taking together all the phylogenetic, genomics, and pathogenicity data obtained in this study from the analysis of P990 genome sequence along with several plant-associated actinobacteria, we provide a novel insight into the genetic diversity of Curtobacterium spp., which suggest a taxonomic revision on the plant pathogenic C. flaccumfaciens strains. Whole genome sequence of P990 would allow us to predict and test which genes are involved in the pathogenicity of the bacterium, providing an opportunity at the same time to develop state-of-the-art genomeinformed detection methods to trace seed infections with lower efforts and cost. Additionally, genomics information will allow us to target $C$. flaccumfaciens pv. flaccumfaciens pathogenicity determinates in the search for developing wilt-resistant lines and cultivars to aid the dry bean industries around the world.

\section{ACKNOWLEDGMENTS}

E. Osdaghi and M. Khojasteh benefited from scientific exchanges and interactions promoted by the Iranian Ministry of Science and Technology.

\section{LITERATURE CITED}

Alikhan, N. F., Petty, N. K., Zakour, N. L. B., and Beatson, S. A. 2011. BLAST Ring Image Generator (BRIG): Simple prokaryote genome comparisons. BMC Genomics 12:402.

Ansari, M., Taghavi, S. M., Hamzehzarghani, H., Valenzuela, M., Siri, M. I., and Osdaghi, E. 2019. Multiple introductions of tomato pathogen Clavibacter michiganensis subsp. michiganensis into Iran as revealed by a global-scale phylogeographic analysis. Appl. Environ. Microbiol. 85:e02098-e2119.

Arndt, D., Grant, J. R., Marcu, A., Sajed, T., Pon, A., Liang, Y., and Wishart, D. S. 2016. PHASTER: A better, faster version of the PHAST phage search tool. Nucleic Acids Res. 44:W16-W21.

Aziz, R. K., Bartels, D., Best, A. A., DeJongh, M., Disz, T., Edwards, R. A., et al. 2008. The RAST Server: Rapid annotations using subsystems technology. BMC Genomics 9:75.

Bentley, S. D., Corton, C., Brown, S. E., Barron, A., Clark, L., Doggett, J., et al. 2008. Genome of the actinomycete plant pathogen Clavibacter michiganensis subsp. sepedonicus suggests recent niche adaptation. J. Bacteriol. 190:2150-2160.

Bertelli, C., Laird, M. R., and Williams, K. P., Lau, B. Y., Simon Fraser University Research Computing Group, Hoad, G., Winsor, G. L., and Brinkmann, F. S. L. 2017. IslandViewer 4: Expanded prediction of genomic islands for larger-scale datasets. Nucleic Acids Res. 45:W30-W35.

Borodovsky, M., and Lomsadze, A. 2014. Gene identification in prokaryotic genomes, phages, metagenomes, and EST sequences with GeneMarkS suite. Curr. Protoc. Microbiol. 32:1E-7.

Brumbley, S. M., Petrasovits, L. A., Hermann, S. R., Young, A. J., and Croft, B. J. 2006. Recent advances in the molecular biology of Leifsonia xyli subsp. xyli, causal organism of ratoon stunting disease. Australas. Plant Pathol. 35:681-689.

Buchfink, B., Xie, C., and Huson, D. H. 2015. Fast and sensitive protein alignment using DIAMOND. Nat. Methods 12:59-60.

Carattoli, A., Zankari, E., García-Fernández, A., Larsen, M. V., Lund, O., Villa, L., Aarestrup, F. M., and Hasman, H. 2014. In silico detection and typing of plasmids using PlasmidFinder and plasmid multilocus sequence typing. Antimicrob. Agents Chemother. 58:3895-3903.

Darling, A. E., Mau, B., and Perna, N. T. 2010. ProgressiveMauve: Multiple genome alignment with gene gain, loss and rearrangement. PLoS One 5: e11147. 
De Bruyne, E., Swings, J., and Kersters, K. 1992. Enzymatic relatedness amongst phytopathogenic coryneform bacteria and its potential use for their identification. Syst. Appl. Microbiol. 15:393-401.

De Jong, A., van Hijum, S. A., Bijlsma, J. J., Kok, J., and Kuipers, O. P. 2006. BAGEL: A web-based bacteriocin genome mining tool. Nucleic Acids Res. 34:W273-W279.

Durbin, R. D. 1972. Bacterial phytotoxins. Pages 19-23 in: Phytotoxins in Plant Disease. R. K. S. Wood, A. Ballio, and A. Graniti, eds. Academic Press, New York, London.

El-Gebali, S., Mistry, J., Bateman, A., Eddy, S. R., Luciani, A., Potter, S. C., et al. 2019. The Pfam protein families database in 2019. Nucleic Acids Res. 47:D427-D432.

EPPO. 2011. Curtobacterium flaccumfaciens pv. flaccumfaciens. Bull. OEPP/ EPPO Bull. 41:320-328.

Evtushenko, L. I., and Takeuchi, M. 2006. The family Microbacteriaceae. Prokaryotes 3:1020-1098.

Gartemann, K. H., Abt, B., Bekel, T., Burger, A., Engemann, J., Flügel, M., et al. 2008. The genome sequence of the tomato-pathogenic actinomycete Clavibacter michiganensis subsp. michiganensis NCPPB382 reveals a large island involved in pathogenicity. J. Bacteriol. 190:2138-2149.

Gross, D. C., and Vidaver, A. K. 1979. Bacteriocins of phytopathogenic Corynebacterium species. Can. J. Microbiol. 25:367-374.

Gross, D. C., Vidaver, A. K., and Keralis, M. B. 1979. Indigenous plasmids from phytopathogenic Corynebacterium species. J. Gen. Microbiol. 115: 479-489.

Harveson, R. M. 2013. The Multicolored Bacterium. APS Features. doi: 10.1094/APSFeature-2013-11

Harveson, R. M., Schwartz, H. F., Urrea, C. A., and Yonts, C. D. 2015. Bacterial wilt of dry-edible beans in the central high plains of the US: Past, present, and future. Plant Dis. 99:1665-1677.

Hedges, F. 1922. A bacterial wilt of beans caused by Bacterium flaccumfaciens nov. sp. Science 55:433-434.

Hendrick, C. A., Haskins, W. P., and Vidaver, A. K. 1984. Conjugative plasmid in Corynebacterium flaccumfaciens subsp. oortii that confers resistance to Arsenite, Arsenate, and Antimony(III). Appl. Environ. Microbiol. 48:56-60.

Huang, H. C., Erickson, R. S., Balasubramanian, P. M., Hsieh, T. F., and Conner, R. L. 2009. Resurgence of bacterial wilt of common bean in North America. Can. J. Plant Pathol. 31:290-300.

Khojasteh, M., Shah, S. M. A., Haq, F., Xu, X., Taghavi, S. M., Osdaghi, E., and Chen, G. 2020. Transcription activator-like effectors diversity in Iranian strains of Xanthomonas translucens. Phytopathology 110:758-767.

Kim, M., Oh, H. S., Park, S. C., and Chun, J. 2014. Towards a taxonomic coherence between average nucleotide identity and 16S rRNA gene sequence similarity for species demarcation of prokaryotes. Int. J. Syst. Evol. Microbiol. 64:346-351.

Kolmogorov, M., Yuan, J., Lin, Y., and Pevzner, P. A. 2019. Assembly of long, error-prone reads using repeat graphs. Nat. Biotechnol. 37:540-546.

Krzywinski, M., Schein, J., Birol, I., Connors, J., Gascoyne, R., Horsman, D., Jones, S. J., and Marra, M. A. 2009. Circos: An information aesthetic for comparative genomics. Genome Res. 19:1639-1645.

Lamichhane, J. R., Osdaghi, E., Behlau, F., Köhl, J., Jones, J. B., and Aubertot, J. N. 2018. Thirteen decades of anti-microbial copper compounds applied in agriculture. A review. Agron. Sustain. Dev. 38:28.

Li, X., Tambong, J., Yuan, K. X., Chen, W., Xu, H., Lévesque, C. A., and De Boer, S. H. 2018. Re-classification of Clavibacter michiganensis subspecies on the basis of whole-genome and multi-locus sequence analyses. Int. J. Syst. Evol. Microbiol. 68:234-240.

Meier-Kolthoff, J. P., Auch, A. F., Klenk, H. P., and Göker, M. 2013. Genome sequence-based species delimitation with confidence intervals and improved distance functions. BMC Bioinformatics 14:60.

Meletzus, D., and Eichenlaub, R. 1991. Transformation of the phytopathogenic bacterium Clavibacter michiganense subsp. michiganense by electroporation and development of a cloning vector. J. Bacteriol. 173:184-190.

Monteiro-Vitorello, C. B., Camargo, L. E., Van Sluys, M. A., et al. 2004. The genome sequence of the gram-positive sugarcane pathogen Leifsonia xyli subsp. xyli. Mol. Plant-Microbe Interact. 17:827-836.

Nelson, P. E., and Dickey, R. S. 1970. Histopathology of plants infected with vascular bacterial pathogens. Annu. Rev. Phytopathol. 8:259-280.

Osdaghi, E., Ansari, M., Taghavi, S. M., Zarei, S., Koebnik, R., and Lamichhane, J. R. 2018b. Pathogenicity and phylogenetic analysis of Clavibacter michiganensis strains associated with tomato plants in Iran. Plant Pathol. 67:957-970.

Osdaghi, E., and Lak, M. R. 2015. Occurrence of a new orange variant of Curtobacterium flaccumfaciens pv. flaccumfaciens, causing common bean wilt in Iran. J. Phytopathol. 163:867-871.
Osdaghi, E., Pakdaman Sardrood, B., Bavi, M., Akbari Oghaz, N., Kimiaei, S., and Hadian, S. 2015b. First report of Curtobacterium flaccumfaciens pv. flaccumfaciens causing cowpea bacterial wilt in Iran. J. Phytopathol. 163: 653-656.

Osdaghi, E., Rahimi, T., Taghavi, S. M., Ansari, M., Zarei, S., Portier, P., Briand, M., and Jacques, M.-A. 2020b. Comparative genomics and phylogenetic analyses suggest several novel species within the genus Clavibacter, including nonpathogenic tomato-associated strains. Appl. Environ. Microbiol. 86:e02873-e19.

Osdaghi, E., Taghavi, S. M., Calamai, S., Biancalani, C., Cerboneschi, M., Tegli, S., and Harveson, R. M. 2018a. Phenotypic and molecularphylogenetic analysis provide novel insights into the diversity of Curtobacterium flaccumfaciens. Phytopathology 108:1154-1164.

Osdaghi, E., Taghavi, S. M., Fazliarab, A., Elahifard, E., and Lamichhane, J. R. 2015a. Characterization, geographic distribution and host range of Curtobacterium flaccumfaciens: An emerging bacterial pathogen in Iran. Crop Prot. 78:185-192.

Osdaghi, E., Taghavi, S. M., Hamzehzarghani, H., Fazliarab, A., Harveson, R. M., and Lamichhane, J. R. 2016. Occurrence and characterization of a new red-pigmented variant of Curtobacterium flaccumfaciens, the causal agent of bacterial wilt of edible dry beans in Iran. Eur. J. Plant Pathol. 146:129-145.

Osdaghi, E., Taghavi, S. M., Hamzehzarghani, H., Fazliarab, A., Harveson, R. M., Tegli, S., and Lamichhane, J. R. 2018c. Epiphytic Curtobacterium flaccumfaciens strains isolated from symptomless solanaceous vegetables are pathogenic on leguminous but not on solanaceous plants. Plant Pathol. 67:388-398.

Osdaghi, E., Young, A. J., and Harveson, R. M. 2020a. Bacterial wilt of dry beans caused by Curtobacterium flaccumfaciens pv. flaccumfaciens: A new threat from an old enemy. Mol. Plant Pathol. 21:605-621.

Overbeek, R., Begley, T., Butler, R. M., Choudhuri, J. V., Chuang, H. Y., Cohoon, M., et al. 2005. The subsystems approach to genome annotation and its use in the project to annotate 1000 genomes. Nucleic Acids Res. 33: 5691-5702.

Overbeek, R., Olson, R., Pusch, G. D., Olsen, G. J., Davis, J. J., Disz, T., et al. 2014. The SEED and the rapid annotation of microbial genomes using subsystems technology (RAST). Nucleic Acids Res. 42:D206-D214.

Richter, M., Rosselló-Móra, R., Oliver Glöckner, F., and Peplies, J. 2016. JSpeciesWS: A web server for prokaryotic species circumscription based on pairwise genome comparison. Bioinformatics 32:929-931.

Rodriguez-R, L. M., and Konstantinidis, K. T. 2016. The enveomics collection: A toolbox for specialized analyses of microbial genomes and metagenomes (No. e1900v1). PeerJ Preprints 4:e1900v1.

Schuster, M. L., and Coyne, D. P. 1981. Biology, epidemiology, genetics and breeding for resistance to bacterial pathogens of Phaseolus vulgaris. Hortic. Rev. (Am. Soc. Hortic. Sci.) 3:28-58.

Sedighian, N., Taghavi, S. M., Hamzehzarghani, H., van der Wolf, J. M., Wicker, E., and Osdaghi, E. 2020. Potato-infecting Ralstonia solanacearum strains in Iran expand knowledge on the global diversity of brown rot ecotype of the pathogen. Phytopathology 110:1647-1656. doi.org/10.1094/ PHYTO-03-20-0072-R

Silver, S., and Misra, T. K. 1988. Plasmid-mediated heavy metal resistances. Annu. Rev. Microbiol. 42:717-743.

Tegli, S., Sereni, A., and Surico, G. 2002. PCR-based assay for the detection of Curtobacterium flaccumfaciens pv. flaccumfaciens in bean seeds. Lett. Appl. Microbiol. 35:331-337.

Thapa, S. P., Davis, E. W., Lyu, Q., Weisberg, A. J., Stevens, D. M., Clarke, C. R., Coaker, G., and Chang, J. H. 2019. The evolution, ecology, and mechanisms of infection by gram-positive, plant-associated bacteria. Annu. Rev. Phytopathol. 57:341-365.

Valdés-Stauber, N., and Scherer, S. 1994. Isolation and characterization of Linocin M18, a bacteriocin produced by Brevibacterium linens. Appl. Environ. Microbiol. 60:3809-3814.

Vidaver, A. K. 1982. The plant pathogenic corynebacteria. Annu. Rev. Microbiol. 36:495-517.

Wang, Y., Coleman-Derr, D., Chen, G., and Gu, Y. Q. 2015. OrthoVenn: A web server for genome wide comparison and annotation of orthologous clusters across multiple species. Nucleic Acids Res. 43:W78-W84.

Wood, B. A., and Easdown, W. J. 1990. A new bacterial disease of mung bean and cowpea for Australia. Australas. Plant Pathol. 19:16-21.

Yoon, S. H., Ha, S. M., Lim, J., Kwon, S., and Chun, J. 2017. A large-scale evaluation of algorithms to calculate average nucleotide identity. Antonie van Leeuwenhoek 110:1281-1286.

Zaumeyer, W. J. 1932. Comparative pathological histology of three bacterial diseases of bean. J. Agric. Res. 44:605-632. 